Original Articles

\title{
Hearing non-signers use their gestures to predict iconic form-meaning mappings at first exposure to signs
}

\author{
Gerardo Ortega $^{\mathrm{a}, *}$, Annika Schiefner ${ }^{\mathrm{b}}$, Aslı Özyürek ${ }^{\mathrm{a}, \mathrm{b}, \mathrm{c}}$ \\ ${ }^{\text {a } U n i v e r s i t y ~ o f ~ B i r m i n g h a m, ~ N i j m e g e n, ~ t h e ~ N e t h e r l a n d s ~}$ \\ ${ }^{\mathrm{b}}$ Centre for Language Studies, Radboud University, Nijmegen, the Netherlands \\ ${ }^{\mathrm{c}}$ Donders Centre for Cognition, Nijmegen, the Netherlands
}

\section{A R T I C L E I N F O}

\section{Keywords:}

Iconicity

Sign language

Gesture

Iconicity ratings

Manualmodality

Form-meaning mappings

\begin{abstract}
A B S T R A C T
The sign languages of deaf communities and the gestures produced by hearing people are communicative systems that exploit the manual-visual modality as means of expression. Despite their striking differences they share the property of iconicity, understood as the direct relationship between a symbol and its referent. Here we investigate whether non-signing hearing adults exploit their implicit knowledge of gestures to bootstrap accurate understanding of the meaning of iconic signs they have never seen before. In Study 1 we show that for some concepts gestures exhibit systematic forms across participants, and share different degrees of form overlap with the signs for the same concepts (full, partial, and no overlap). In Study 2 we found that signs with stronger resemblance with signs are more accurately guessed and are assigned higher iconicity ratings by non-signers than signs with low overlap. In addition, when more people produced a systematic gesture resembling a sign, they assigned higher iconicity ratings to that sign. Furthermore, participants had a bias to assume that signs represent actions and not objects. The similarities between some signs and gestures could be explained by deaf signers and hearing gesturers sharing a conceptual substrate that is rooted in our embodied experiences with the world. The finding that gestural knowledge can ease the interpretation of the meaning of novel signs and predicts iconicity ratings is in line with embodied accounts of cognition and the influence of prior knowledge to acquire new schemas. Through these mechanisms we propose that iconic gestures that overlap in form with signs may serve as some type of 'manual cognates' that help non-signing adults to break into a new language at first exposure.
\end{abstract}

\section{Introduction}

Recent developments in the language sciences have convincingly demonstrated that iconicity is not a marginal phenomenon but rather is an important feature of language that can be observed in all its modalities (i.e., speech, gesture, and sign) (Dingemanse, Blasi, Lupyan, Christiansen, \& Monaghan, 2015; Perniss \& Vigliocco, 2014; Perniss, Özyürek, \& Morgan, 2015). The discussion is no longer whether iconicity in its multiple formats is a prevalent characteristic of language, but rather the debate has shifted towards trying to explicate the mechanisms that facilitate the mapping, processing, and learning of iconic forms in different modalities. In the spoken modality, one explanation posits that certain sounds recurrently co-occur with specific sensorimotor events and individuals tune to these sound-symbolic mappings due to probabilistic associations (Sidhu \& Pexman, 2017). Regarding co-speech gestures, it has been argued that iconicity activates imagistic features of our conceptual representation and facilitates processing of arbitrary spoken words (de Ruiter, 2007; Drijvers \& Ozyürek, 2017; Kelly, Özyürek, \& Maris, 2010; Krauss, 1998; Özyürek, Willems, Kita, \& Hagoort, 2007; Yap, So, Yap, Tan, \& Teoh, 2011). In sign languages, it has been suggested that access to sign iconicity is a subjective, culturespecific process that is tightly linked to signers' experience with their sign language (Occhino, Anible, Wilkinson, \& Morford, 2017; Pizzuto \& Volterra, 2000), and this in turn facilitates processing (Vinson, Thompson, Skinner, \& Vigliocco, 2015).

This paper attempts to understand the possible relations between two of these areas by investigating whether iconicity in one domain of language (i.e., gesture) can serve as a gateway to interpret iconic forms in another (i.e., sign). More specifically, we investigate whether the iconic gestures used by non-signing hearing speakers can assist in making accurate form-meaning associations of iconic signs never seen before.

\footnotetext{
* Corresponding author at: University of Birmingham, English Language and Linguistics, 3 Elms Road, Birmimgham B15 2 TT, UK.

E-mail address: g.ortega@bham.ac.uk (G. Ortega).
} 
Multiple empirical studies have consistently demonstrated that iconicity in lexical signs has a positive effect in hearing non-signers' recall, learning, naming, and translating compared to arbitrary ones (Baus, Carreiras, \& Emmorey, 2012; Campbell, Martin, \& White, 1992; Lieberth \& Gamble, 1991). However, these findings are paradoxical given that non-signers have limited access to the iconic features of signs and perform poorly when asked to guess their meaning in isolation (Griffith, Robinson, \& Panagos, 1981; Klima \& Bellugi, 1979). It has been argued that hearing non-signers lack cultural and linguistic experience with a manual language and thus they cannot penetrate the iconic features of signs (Klima \& Bellugi, 1979). However, while it is true that hearing non-signers rely on speech as the primary source of linguistic information, they also have experience with the manual modality through their gestures. Thus, we ask here whether gesture is a plausible semiotic resource hearing non-signers can bootstrap on to make associations between iconic signs and their meaning.

Gestures and signs differ from each other in significant ways: signs are conventionalised systems with linguistic organisation (Sandler \& Lillo-Martin, 2006) whereas gestures are communicative manual structures without the same degree of conventionalisation (GoldinMeadow \& Brentari, 2017; Kendon, 2004; McNeill, 1992). However, both signs and gestures share the property of iconicity in that they can mimic the visual properties of events, objects, and spatial relations, and in many instances they may converge in form and meaning due to the shared affordances of the manual-visual modality (Padden, Hwang, Lepic, \& Seegers, 2015; Perniss et al., 2015; Vigliocco, Perniss, \& Vinson, 2014). Their similarities may even be augmented when we look at silent gestures, which are manual articulations which adopt sign-like properties when produced in the absence of speech (Goldin-Meadow \& Brentari, 2017; Goldin-Meadow, McNeill, \& Singleton, 1996).

If indeed non-signers have at their disposal a gestural repertoire with similar forms across individuals, it may be possible that they could exploit them to make judgements about the meaning of signs as well as their meaning transparency (i.e., how well a manual form represents a concept). In this study, we characterise the silent gestures of a group of adults with no knowledge of a sign language and test whether similarities in form between signs they see for the first time and their own gestures predict their ability to make judgements about the meaning and degree of iconicity of signs.

\subsection{Perception of sign iconicity by hearing non-signers}

Iconicity in sign languages has been argued to be a ubiquitous property that can be observed at multiple levels of linguistic organisation, in particular, in the lexicon (Cuxac, 1999; Pietrandrea, 2002; Taub, 2001). But despite its omnipresence, hearing non-signers do not seem to be capable of linking the referent with the iconic features depicted in signs. In their seminal study, Klima and Bellugi (1979) asked hearing non-signing adults to guess the meaning of a set of common signs in American Sign Language (ASL) that could be easily translated into English. When signs were presented in isolation and participants had to write down their meaning, they showed a very low success rate (less than 10\%). However, when they were presented with the sign along with its English translation and had to explain the iconic relationship between them they showed significant improvement. Participants showed overall agreement because they were able to accurately describe the iconic motivation of more than $50 \%$ of the signs but only when they were given their meaning (e.g., most participants agreed that the sign VOTE depicted a person putting a ballot in a box). However, this was not always the case because non-signers were often unaware of the historical iconic instantiation of some signs and generated inaccurate meaning relations (e.g., the sign GIRL was associated with the softness of a girl's cheek but it is actually related to the straps of a bonnet). This study set a benchmark in sign language research and persuasively argued that iconicity is not a binary property of signs; and while non-signers may be able to identify the form-meaning relationship of some signs with a cue, they tend to yield low accuracy when guessing the meaning of signs in isolation.

Recent research suggests that perception of iconicity 'is in the eye of the beholder' because it is based on individuals' world knowledge and experience with the language itself (Occhino et al., 2017). For example, the sign PIANO in many sign languages often represents the tapping on the piano keys but the ability to link the manual form with the referent will depend on individuals' knowledge of the musical instrument (Occhino et al., 2017). Similarly, the O handshape of the ASL sign OFFICE does not reflect the shape of an office, and yet ASL signers regard it as highly iconic because of the language-specific construal of the sign. Therefore, only experience with ASL may give access to the way signs tap into the iconic feature of referent. As the authors put it it is only through shared cultural experiences that these patterns of shared construal allow for conventionalised cultural interpretation of formmeaning mapping' (Occhino et al., 2017; p. 10). The lack of shared experiences with a sign language may undermine non-signers capacity to interpret the iconic features of signs never seen before.

In the context of this previous research, one study highlights the possibility that non-signers' knowledge of their own gestures might help them guess the meaning of signs. Grosso (1993) showed a set of iconic and arbitrary signs in Italian Sign Language (LIS) to hearing nonsigning speakers and asked them to guess their meaning. Participants could not provide a correct response for a large proportion of signs (76\%) but they were very accurate for a considerable number of items on the list (24\%). A detailed analysis of the correctly guessed items revealed that these signs resemble emblems commonly used by Italian speakers (e.g., the sign GOOD has the same form and meaning as the emblem used by Italian speakers). Emblems have a conventionalised, culture-specific form and meaning (Kendon, 1995, 2004). When nonsigning adults are confronted by signs that overlap in structures, they rightly assume that they also share the same meaning. This study is one of the first to suggest that non-signers' ability to guess the meaning of signs is based on the structural similarities between conventionalised signs and the gestures produced by the surrounding speaking community.

A limitation of this study is that it presupposes that only emblems facilitate the accurate guessing of the meaning of signs but does not say how other types of gestures may also be recruited for the same purposes. Emblems have highly conventionalised hand configurations, are used for specific pragmatic purposes (Kendon, 1995, 2004), and have mental representations akin to those of abstract words (Gunter \& Bach, 2004). As such, they are gestural entities easy to retrieve and that can be compared with conventionalised signs. It remains an empirical question whether iconic gestures, which are spontaneous creations shaped by their analogical links to the referent (Goldin-Meadow \& Brentari, 2017), may also be used as a basis to make judgments about the meaning of signs.

Iconicity is commonly exploited in the gestures produced by hearing non-signers and in many instances these gestures may align in form with the iconic features depicted in signs. We propose that hearing nonsigners generate expectations about how a concept should be represented in a sign language based on how they would express the concept in gesture. When they are confronted with conventionalised signs for the first time they will not make judgements about their meaning in a vacuum but rather they are likely to fall back on their own gestures to make sign-meaning associations.

\subsection{Iconicity and systematicity ${ }^{1}$ in the manual modality}

A series of studies have given some initial evidence that despite their spontaneous nature, there are generalizable patterns in the way

\footnotetext{
${ }^{1}$ In the rest of the manuscript we will use the term 'systematicity' to refer to the consistency in gestural forms across a pool of participants.
} 
sign and gesture exploit iconicity to depict concepts. Both forms of manual communication have been reported to use similar representational strategies whereby the body can represent human motion (i.e., acting or handling); the hands may adopt different configurations to reflect the shape of objects (i.e., representing or instrument), or the hands can trace the outline of the referent (drawing or tracing) (Müller, 2013, 2016; Padden et al., 2013, 2015). The notion of patterned iconicity suggests that sign languages deploy specific types of iconicity according to the semantic domain they pertain and thus this constitutes the basis of grammatical distinctions (Kimmelman, Klezovich, \& Moroz, 2018; Padden et al., 2015, 2013). For instance, it has been argued that in some sign languages, the acting strategy is commonly used to refer to actions (verbs) whereas the representing strategy is used to refer to objects (nouns) (Padden et al., 2015, 2013). While this differentiations has not been observed in silent gesture (e.g., Ortega \& Özyürek, 2019; Van Nispen, Van De Sandt-Koenderman, \& Krahmer, 2017) the similarities in how gesture and sign represent concepts iconically support claims that both forms of manual communication share a common basis (Kendon, 2004, 2008). This common ground could give hearing nonsigners some leverage to recognise signs never seen before through their gestural knowledge.

It could be argued that iconic gestures are an unreliable resource to make judgements about the meaning of signs because they are highly idiosyncratic and individuals vary significantly in the way they represent a concept in the manual modality. However, recent studies have demonstrated that gestures, especially those produced in the absence of speech, are more systematic than previously assumed. Silent gesture stands out because they exhibit features not observed in the gestures cooccurring with speech (Goldin-Meadow et al., 1996) and their sequencing aligns across speakers of different languages (Christensen, Fusaroli, \& Tylén, 2016; Gibson et al., 2013; Goldin-Meadow, So, Ozyürek, \& Mylander, 2008; Hall, Mayberry, \& Ferreira, 2013; Meir et al., 2017; Schouwstra \& De Swart, 2014).

Relevant to this study is the finding that individuals often resort to similar iconic strategies to represent the same concepts in silent gesture (Ortega \& Özyürek, 2016, 2019; Van Nispen et al., 2017). Ortega and Özyürek (2019) created a database of elicited silent gestures from Dutch adults and they found that participants employ remarkably similar strategies to depict referents. Through the implementation of specific types of iconic depictions and their combinations, participants systematically represent concepts across different semantic domains. Relevant to this study is the finding that not only do people produce remarkably similar gestures to represent objects in silent gestures, but also those gestures tend to be better guessed by an interlocutor (Van Nispen et al., 2017). Interestingly, the preferred form of iconic representation tends to reflect actions associated with the referent regardless of whether it is an action or an object (e.g., the concept 'beer' is often depicted by mimicking the motion of drinking from a glass). This action-based preference echoes findings in developmental psychology that show that deaf and hearing children exhibit a bias to produce and comprehend manual forms representing bodily actions (Ortega, Sümer, \& Ozyürek, 2017; Pettenati, Sekine, Congestrì, \& Volterra, 2012. See also Brentari, Renzo, Keane, \& Volterra, 2015). This would suggest that humans have a natural bias to depict and perceive concepts as representations of human action.

But where does this consistency in gestural production come from? One could speculate that two factors may be responsible for the similarities in gestural forms for certain concepts across a population. One of them could be the affordances of the modality (Perniss et al., 2015). Signs and gestures are physically constrained by the capabilities of what can be expressed with the body and some properties can be easily represented (e.g., shapes of objects) while some features cannot (e.g., colour and sound). In that sense, the affordances of the body set the degrees of freedom of an iconic representation and motivate the representation of certain features over others.

The second factor may be our shared conceptual substrate. It has been suggested that iconic manual representations are generated by selecting salient features of the referent from our conceptual knowledge (e.g., the wings of a butterfly), schematizing them into a manual structure (e.g., linking the wings with human arms), and producing an iconic gesture that evokes the selected features (e.g., flapping arms to represent a butterfly) (Emmorey, 2014; Taub, 2001; Van Nispen et al., 2017). If we ascribe to embodied theories of gesture production (Cook \& Tanenhaus, 2009; Hostetter \& Alibali, 2008; Kita, Alibali, \& Chu, 2017) and assume that our conceptual knowledge is grounded in motor schemas (Barsalou, 1999, 2008; Lagacé \& Guérard, 2015) then it is likely that many gestures may converge in the form to represent a concept. Therefore, the affordances of the manual modality as well as our shared mental schemas may be the two forces that come together and result in iconic gestures that converge in form and meaning across a group of individuals.

This line of reasoning has important implications for research investigating how modality shapes all types of manual structures (i.e., sign and gesture) (Perniss et al., 2015). If both deaf signers and hearing gesturers share the same conceptual representations as well as the same constraints of the manual-visual modality, there may be a number of iconic signs that overlap in form and meaning with some of the gestures of the surrounding speaking community. Signs and gestures may bear enough form overlap with signs and as a result hearing non-signers may be able to guess signs' meaning despite their lack of experience with a sign language. Indeed, recent evidence has demonstrated that novice sign language learners draw from their gestural repertoire at the earliest stages of sign production (Janke \& Marshall, 2017; Marshall \& Morgan, 2015). However, it has not yet been investigated the degree of systematicity of silent gestures for specific concepts and how they contribute towards the interpretation of the meaning of signs.

\subsection{The present study}

Iconicity and the extent to which sign-naïve adults can access the meaning of iconic signs has been a central focus of attention in research. Based on evidence that many iconic gestures are highly systematic across individuals (Ortega \& Özyürek, 2016, 2019; Padden et al., 2015, 2013; van Nispen, van de Sandt-Koenderman, Mol, \& Krahmer, 2014) it is possible to assume that hearing non-signers share implicit knowledge of gestures for some concepts with specific forms and meanings on which they may base their judgment about signs.

In order to test these hypotheses, we investigated, first, whether non-signers have at their disposal a repertoire of systematic iconic gestures with similar forms across a group, and the extent to which signs and gestures for the same concepts overlap in form (Study 1). We then investigated whether similarities in form between sign and gesture predict non-signers' ability to make judgements about the meaning of signs (Study 2).

In Study 1 we elicited silent gestures from non-signing adults to determine which gestures were the most systematic across participants based on regularities on their gestural forms. Once these gestures were selected, we compared them to signs from Sign Language of the Netherlands (NGT) for the same concept and explored their degree of overlap between them. We categorised signs according to the number of phonological parameters (i.e., handshape, location, movement, and orientation) (Brentari, 1999; van der Kooij, 2002) that overlapped in structure with the four corresponding features that describe gestural forms $^{2}$ (Bressem, 2013). This categorisation resulted in signs that overlapped completely with the form of gestures (full overlap), signs

\footnotetext{
${ }^{2}$ In this paper we subscribe to the notion that only sign languages consist of meaningless sub-lexical components. However, applying the concept of sign phonology to gesture research has been useful to elucidate on the similarities between both forms of manual communication (Bressem, 2013; Ladewig \& Bressem, 2013).
} 
that differed in one phonological parameter (partial overlap), and signs that shared no structural similarities with gestures (no overlap). These signs served as stimulus materials for Study 2 .

In this second study, a different group of participants were presented with these three sets of signs (i.e., full, partial, and no overlap with the systematic gestures) and were asked, first, to guess their meaning. After they gave their response, they were given the correct translation, and then were asked to make judgements about the signs' meaning transparency (i.e., iconicity ratings). The prediction is that when signs have more overlap with the previously collected systematic gestures, non-signing adults will be more accurate at guessing their meaning and will assign higher iconicity ratings. Furthermore, if indeed there is a bias towards the representation of actions associated with a referent (van Nispen et al., 2014) one may predict that non-signers will often assume referents are actions as opposed to objects. The expected results will lend credence to the hypothesis that sign-naïve adults base their responses not only on their emblems (Grosso, 1993), but also on other types of gestures.

\section{Study 1: systematicity in silent iconic gestures}

\subsection{Methodology}

\subsubsection{Participants}

Twenty native speakers of Dutch (10 females, age range: 21-46, mean: 27 years) living in the area of Nijmegen, the Netherlands, took part in the study.

\subsubsection{Procedure}

Participants were seated in front of a computer and were asked to produce a gesture that conveyed exactly the same meaning as a word in Dutch in the middle of the screen. They were explicitly told that it was not allowed to speak or point at any object in the room and that they could say 'pass' if they were unable to generate a gesture. They were told that there was no correct or wrong answer, and importantly, that their gestures would be shown to another person who would have to interpret their meaning. Two cameras were positioned on each side of the participant to record their gestural productions. Trials started with a fixation cross $(500 \mathrm{~ms})$ followed by the target word $(4000 \mathrm{~ms})$ time during which they had to produce their gesture. After the $4000 \mathrm{~ms}$ lapsed, the next trial began. The motivation behind this strict timing was to elicit participants' most intuitive response. The stimuli consisted of a total of 272 words across several semantic domains (119 actions, 104 objects, 49 animate entities). Each testing session lasted approximately $30 \mathrm{~min}$.

\subsubsection{Coding and analysis}

After data collection, all participants' renditions were coded using the linguistic annotator ELAN (Sloetjes \& Wittenburg, 2018). Participants often produced a single gesture but they also produced sequences of meaningful gestures for a single concept. Each isolated gesture consisted minimally of a preparation phase, a stroke, and a partial or full retraction depending on whether gestures were produced as a single rendition (Kita, van Rijn, \& van der Hulst, 1997). Once all meaningful gestures were segmented, their structural form was annotated according to an existing notation system (Bressem, 2013). This notation system is loosely based on the phonological parameters of signs and suggests that gestural forms can be defined by describing their main four features (i.e., the hand configuration, the orientation of the hand, the movement, and the placement in gestural space). For example, if the gesture for the concept 'to smoke' evokes the mimicking of a person smoking a cigarette, its gestural form could be described by with a \{ handshape (i.e., hand configuration), palm facing the body (i.e., orientation), and arced movement towards the mouth (i.e., movement and location, respectively).

After annotating all gestural forms we investigated whether there were a set of systematic gestures that could be generalised across participants. To that end, we operationalised systematicity on the basis of the form across gestures. To the best of our knowledge, there is no standard methodology to operationalise systematicity in gesture productions so we set a threshold based on a pilot study. Based on our observations, we established that a concept would elicit a systematic gesture when at least $60 \%$ of participants produced a gesture that overlapped in minimally three of its features (i.e., the hand configuration, the orientation of the hand, the movement, and the placement in gestural space). The $60 \%$ threshold is different from other studies in that we focus on the formational features of gestures and not the iconic strategies (e.g., Padden et al., 2013; Van Nispen et al., 2017). Our criteria is very stringent because the gesture generation task is an openended, creative exercise with an endless number of possibilities in gesture production. As such, it is quite challenging to converge on the same gestural form. Further, this criterion allowed us to include enough data points across conditions to perform advanced statistical analyses.

In our study, if the same gestural structure was produced by at least 12 out of 20 participants, it was considered the systematic gesture for that concept. If 11 or fewer participants produced the same form, then we concluded that this concept failed to elicit a systematic gesture. For example, for the concept 'to cut with scissors' (knippen in Dutch) most participants produced a $\mathrm{V}$ handshape with open-close movement and the hand following a straight trajectory in gestural space (see Fig. 1). The high prevalence of this gestural form fulfilled our selection criteria and thus it was considered a systematic gesture for that concept. In contrast, the concept 'to eat' (eten) had very disparate forms across participants because not 12 participants converged in the gestural form. As a result, this concept was not included in the set of systematic gestures. For those instances in which participants produced more than one gesture for a given concept, we only considered the gestural structure that was more consistently produced across participants. For example, for the concept 'laptop' most participants mimicked the action of typing on a keyboard in a single gesture, but some others added the tracing of a rectangle after it. Given that most participants produced more frequently the former and not the latter, the typing gesture was the only one included as the systematic gesture.

The set of systematic gestures was then compared to their NGT sign equivalent to determine the different degrees of form overlap. To date there is no NGT sign database to determine the dominant variant for the concepts used in this study from a corpus-based perspective. For this reason we consulted a native signer who has used NGT all his life and is actively involved with the Deaf community in the Netherlands. He was asked to serve as a model to film the 272 sign translations (Amsterdam variant) for the concepts included in the study (without mouthings to avoid giving away any information about the meaning of the sign). A second deaf signer was consulted to confirm whether these signs were typical variants produced by the Dutch deaf community. Signs that were not recognised by the second signer $(n=3)$ were excluded from the study. The aim of this comparison was to quantify the number of signs that overlapped in form with the systematic gestures produced by the non-signing participants.

\subsection{Results}

Participants did not seem to struggle with the gesture generation task because they produced gestures for around $92 \%$ of all trials (444 passes out of 5440 trials). Therefore there were 4996 gestural descriptions that were described in their four main features (Bressem, 2013). This analysis resulted in a total of 145 systematic gestures (64 objects, 58 actions, and 23 animate entities) leaving out 127 concepts that did not elicit a systematic gesture.

After comparing gesture-sign similarities, three different categories were generated. Signs with full overlap were those in which the systematic gesture and the sign overlapped in all its parameters/features (e.g., 'to cut with scissors'; see Fig. 1). Signs with partial overlap where 


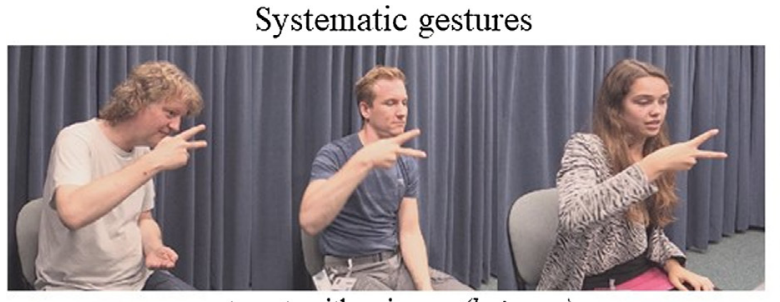

to cut with scissors (knippen)

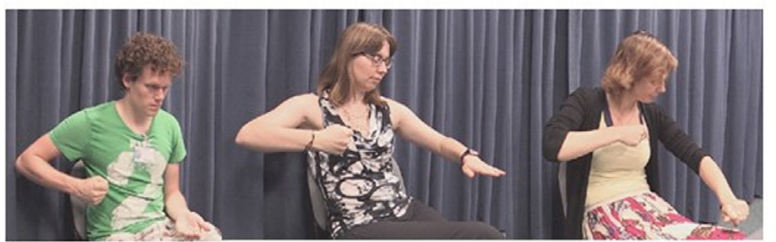

to saw (zagen)

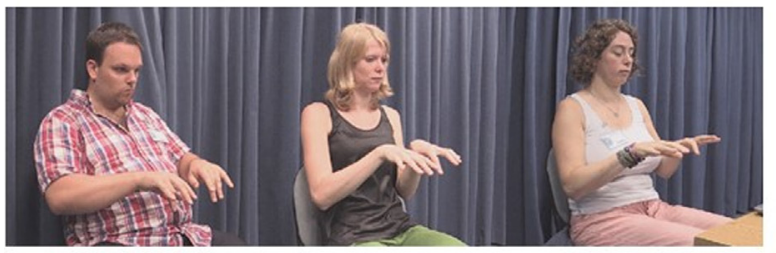

laptop (laptop)

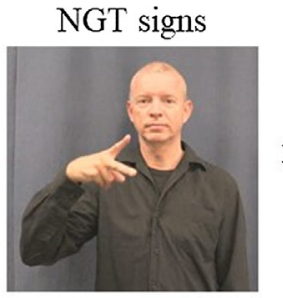

Full overlap

$(\mathrm{N}=36)$
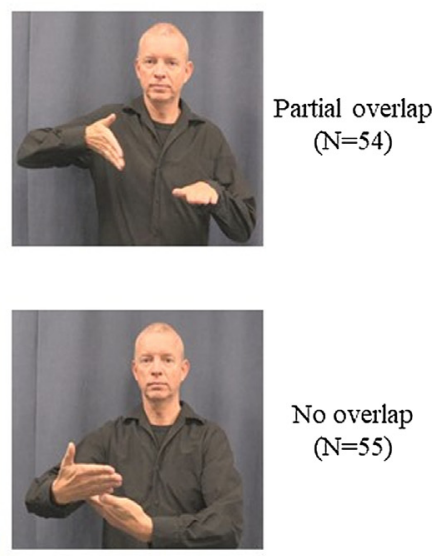

No overlap

$(\mathrm{N}=55)$
Fig. 1. Examples of sign-gesture pairs with different degrees of overlap. The sign TO-CUT-WITH-SCISSORS shares all its phonological components (handshape, location, movement, and orientation) with the features of the systematic gesture (full overlap). The sign TO-SAW consists of an open palm handshape while the gesture for the same concept is a closed fist (partial overlap). The sign LAPTOP does not share any parameter with the gesture (no overlap). those that differed in one parameter with the systematic gesture. For example, for the concept 'to saw' (zagen) gesturers tended to produce a closed fist that mimicked the motions of cutting with a saw. In contrast, the NGT sign was produced with the same motion, in the same location, and orientation, but the hand configuration was an extended open palm (see Fig. 1). Signs with no overlap did not share any phonological parameter with the features of the systematic gesture. For example, while the gesture for 'laptop' consists of a two-handed gesture emulating the action of typing, the NGT signs equivalent consists of two open palms overlapping on the edges and representing the screen and keyboard (see Fig. 1). The comparison between gestures and signs resulted in the following items: Full overlap $=36$ signs; partial overlap $=54$ signs; no overlap $=55$ signs. $^{3}$ Table 1 represents the distribution of systematic gestures according to the type of overlap with the sign (full, partial, no overlap) and semantic domain (actions, objects).

\subsection{Interim discussion}

These results confirmed that for a set of concepts, non-signing hearing adults have a repertoire of iconic gestures that share the same form across participants. There was a large number of items that did not elicit systematic gestures within our inclusion criteria but nevertheless for a considerable proportion of concepts participants converged in the gestural form to depict a concept. The comparisons of these gestural systematic structures with the conventionalized signs for the same concepts revealed that there was also significant overlap with some items. Some of the gestures had the same form as signs (i.e., full overlap), some others shared all but one of their features (i.e., partial overlap), but for other sign-gesture pairs there was no resemblance (i.e., no overlap). This clearly indicates that sign-naïve adults have at their disposal a set of iconic gestures $(n=145)$ that can be generalised across the population, and importantly, that some of them have remarkably

\footnotetext{
${ }^{3}$ The mean number of participants producing a systematic gesture for each condition is as follows: Full overlap $=16.13$ participants; partial overlap = 16.24 participants; no overlap $=13.59$ participants. The range in all conditions was $12-20$ participants.
}

similar form and meaning to conventionalised signs referring to the same concept.

This raises the question whether sign-gesture similarities could facilitate non-signers' ability to guess the meaning of signs, and perhaps predict their judgements about their meaning transparency. The prediction is that non-signers will be accurate at guessing the meaning of signs in the full overlap condition because they match with the manual structure typically produced by the hearing community for the same concept. Signs in the no overlap condition should be more difficult to guess because there will be a mismatch between the sign and the systematic gesture.

Regarding the signs in the partial overlap condition, there are two possible predictions. One is that hearing non-signers will not be sensitive to signs' phonological units and will perceive that signs bear enough resemblance with the systematic gesture and thus will be accurate at guessing their meaning. On the other hand, it is possible that even this subtle difference will confuse participants and will make them assume that the meaning of the sign does not relate to their gesture but to another concept and as a result will reduce their accuracy. Furthermore, based on research showing a bias towards production of iconic depictions of bodily actions (Ortega \& Özyürek, 2016; Van Nispen et al., 2017), participants are likely to assume that referents are actions instead of objects, even for signs referring to objects.

\section{Study 2: the influence of gesture in the perception of sign iconicity}

\subsection{Methodology}

\subsubsection{Participants}

The participants of this study were a different group of 20 hearing native speakers of Dutch ( 14 female, mean age $=21.8$ years) with no knowledge of NGT or any other sign language. None of them took part in the gesture generation task of Study 1 .

\subsubsection{Stimuli}

The stimuli consisted of videos of the 145 NGT signs selected from Study 1 ; i.e., signs in the full overlap condition $=36$ signs; partial 
Table 1

Distribution of systematic gestures according to overlap with the NGT sign equivalent (full, partial, no overlap) and semantic domain.

Systematic gestures by type of overlap and semantic domain

\begin{tabular}{|c|c|c|c|c|c|c|}
\hline & Actions with object & Actions without object & Animate entities & Manipulable objects & Non-manipulable objects & TOTAL \\
\hline Full overlap & 7 & 12 & 4 & 8 & 5 & 36 \\
\hline Partial overlap & 17 & 6 & 5 & 19 & 8 & 54 \\
\hline No overlap & 4 & 12 & 14 & 13 & 11 & 55 \\
\hline TOTAL & 28 & 30 & 23 & 40 & 24 & 145 \\
\hline
\end{tabular}

overlap $=54$ signs; no overlap $=55$ signs. Videos were produced by a deaf signer with neutral face and without mouthings to avoid giving away cues about the meanings of the signs.

\subsubsection{Procedure}

The study consisted of an open-cloze and iconicity rating tasks. At the beginning of each trial, an individual NGT sign was presented. After the video had played in full and disappeared from the screen, a new screen was presented instructing participants to type in the meaning of the sign they had just seen (open-cloze). Participants were required to type an answer in one word for every sign but they were also allowed to skip signs if they could not come up with a meaning. After participants had entered an answer, a new screen of instructions came up. Here participants were given the actual meaning of the sign and were asked to judge how well the sign represented its meaning (iconicity ratings). The screen displayed a 7-point Likert scale and participants were required to type in their rating. The anchors were 1 to represent the lowest similarity and 7 the highest (see Appendix $C$ for the full set of instructions).

\subsubsection{Analysis}

In the open-cloze task, participants gave a response for a large proportion of the signs with passes representing only $6.5 \%$ of the responses. Despite being instructed to write only one word, some responses were two-word phrases, but they were still included in the analysis since they always represented single concepts. Based on the Dutch version of the Boston Naming Task (Roomer, Hoogerwerf, \& Linn, 2011), answers were coded as correct or incorrect. Answers were coded as correct if they matched exactly the expected answer (e.g., sign: TO-PULL ${ }^{4}$; response: 'to pull') or if they were synonyms of each other (e.g., sign: TO-PHONE; response: 'to call'). This category also included answers that were not the same part of speech as the target sign, but where the answer was specific to the target concept (e.g., sign: TOPHONE; response: 'telephone' $)^{5}$. We also included phrases containing a verb and the correct argument depicted in the sign (e.g., sign: BANANA; response: 'to peel a banana'). Responses that did not fit into any of these categories were classed as incorrect answers.

Incorrect answers included responses that did not refer to the specific target but belonged to the same semantic domain; e.g., DUCK (target sign) and 'penguin' (response) are both animate entities but they refer to different types of birds. Incorrect answers also included responses that lacked the appropriate abstraction to the target concept (e.g., the sign MONKEY, which re-enacts how a primate scratches the sides of its torso, was often labelled as 'scratching'). We also included responses that were plainly wrong, or answers which derived from visual information in the sign, but that had no relationship with the concept (e.g., the sign CAMEL describes the outline of two horizontal bumps, but it was often interpreted as a 'mountain'). A full description

\footnotetext{
${ }^{4}$ Still images of the NGT signs described in the manuscript can be found in Appendix IV.

${ }^{5}$ In Dutch, verb/noun distinctions are differentiated through affixes to the root. For example, telefoneren (to phone) is a verb and telefoon (telephone) is a noun. The English translations do not reflect that participants responded with a single word.
}

of the coding criteria can be found in Supplementary Materials. Two researchers were responsible for coding independently the whole dataset. After they concluded their own coding, disagreements were discussed until both converged in their responses. Accuracy was thus coded as a binary feature.

Considering previous research showing speakers' bias towards depictions of actions associated to a referent (Ortega \& Özyürek, 2016; Van Nispen et al., 2017), we explored whether participants would exhibit such biases in their responses. That is, whether they would assume that referents are actions as opposed to objects. To that end, we included semantic domain as an additional variable. Items were coded as actions (e.g., TO-SMOKE, $\mathrm{N}=58$ ) or objects (e.g., GUITAR, $\mathrm{N}=64$ ). Items referring to animate entities were coded as missing values (e.g., BIRD) because they do not fit into either semantic domain $(\mathrm{N}=23)$.

As for iconicity ratings, we estimated the mean value of each sign through the average of the response of each participant for each sign and across conditions.

Statistical analyses of the accuracy in guessing the meaning of signs (open-cloze) and iconicity ratings across items and participants were conducted in R (Version 3.5.1) (R Core Team, 2018) in Rstudio (Version 1.1.456) (Rstudio Team, 2016). We analysed the accuracy of response data using general mixed-effects regression with a logistic link (GLMER, binomial, lme4 version 1.1-18-1, Bates, Maechler, Bolker, \& Walker, 2015). To examine iconicity ratings, we used linear mixed-effects regression (Baayen, Davidson, \& Bates, 2008; Bates et al., 2015) with Satterthwaite's method for significance testing on t-tests (Singmann, Bolker, Westfall, \& Aust, 2019). For both models, we used forward selection to identify those predictors that significantly contributed to the model. The data and the script in $\mathrm{R}$ of the statistical analysis in freely available at the Open Science Framework repository (Ortega, Schiefner, \& Ozyurek, 2019) (https://osf.io/xc8ab/).

\subsection{Results}

\subsubsection{Open-cloze}

Performance on the open-cloze task was highly variable across participants and items. While only nine items (6.2\%) were correctly identified by all participants, half of the signs (73 signs) were correctly identified by at least $25 \%$ of participants. For 26 items (17.8\%), all answers were semantically related to the target meaning, suggesting that participants were able to correctly identify some aspect of the sign but did not fully identify the exact intended meaning (e.g., sign: MONKEY; response: 'scratching').

In order to evaluate the role of gesture in predicting accuracy to guess the meanings of signs, we created raincloud plots to visualise the distribution of the data. These graphic representations consist of a density curve, combined with the individual data points representing single signs distributed according to the proportion of participants who gave accurate responses for that sign. Fig. 2 shows that accurate responses are relatively evenly distributed in the full and partial overlap conditions, with denser concentration of items towards the lower end for partial than for full overlap signs. However, signs with no overlap with gesture seem to be more difficult to guess across participants, reflected in a strong concentration of data points at the low end of the scale. 


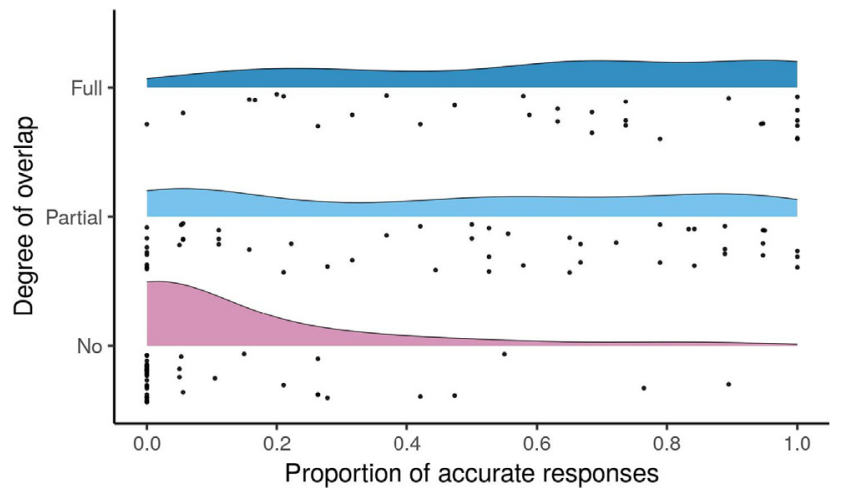

Fig. 2. Raincloud plots displaying the distribution of the proportion of accurate responses as a function of degree of overlap between a sign and the elicited systematic gesture (full, partial and no overlap). Wider sections of the rainclouds indicate higher concentration of data points along the accuracy axis.

Table 2

Estimates, standard error, and z-values of the main effects of the model assessing what factors significantly predict participants' accuracy in guessing the meaning of NGT signs.

\begin{tabular}{lllll}
\hline & \multicolumn{4}{l}{ Accuracy guessing the meaning of signs } \\
\cline { 2 - 5 } Predictor & $\beta$ & $S E$ & $z$ & $\operatorname{Pr}(>|z|)$ \\
\hline Intercept & -6.517 & 1.994 & -3.269 & 0.001 \\
Overlap 0 (ref. 1) & -5.342 & 1.018 & -5.246 & $<0.0001$ \\
Overlap 2 (ref. 1) & 2.177 & 0.977 & 2.230 & 0.026 \\
Degree systematicity & 7.852 & 2.163 & 3.630 & 0.0003 \\
Semantic domain object (ref. & -1.509 & 0.815 & -1.853 & 0.06 \\
$\quad$ action) & & & &
\end{tabular}

Accuracy $\sim$ Overlap + Degree systematicity + Semantic domain $+(1 \mid$ Subject $)$ $+(1 \mid$ VIDEO).

The statistical analysis supported the visualisation of the data. The most parsimonious model for accuracy to guess the meaning of signs incorporated random intercepts for participants and items in the random-effects structure, and main effects for the degree of overlap (i.e., full, partial, or no overlap, with partial overlap as intercept condition), the proportion of participants producing the same systematic gesture for a concept (i.e., degree of systematicity), and semantic domain (i.e., actions, objects). The relevant statistics and corresponding coefficients for the final model are reported in Table 2.

First, we report the analysis on the mean proportion of accurate responses per item across conditions. Accuracy in guessing the meaning of signs with no overlap with gesture $(M=0.118, S D=0.323)$ was lower than for those with partial overlap $(M=0.458, S D=0.498)$. Full overlap $(M=0.610, S D=0.488)$, in turn, had higher accuracy than partial overlap. The model also revealed that accuracy was higher when a higher number of participants produced a systematic gesture for a concept (i.e., degree of systematicity). Finally, signs for objects $(M=0.273, S D=0.445)$ were guessed less accurately than actions $(M=0.503, S D=0.500)$. For instance, participants often assumed that signs for objects (e.g., SPOON) referred to semantically associated actions (e.g., to eat). No interaction effects were found to significantly improve the model. These data suggest that higher degree of overlap with gesture as well as higher degree of consistency in gesture production across a population facilitate guessing the meaning of signs. Further, signs for actions are more easily guessed than signs for objects. Appendix A includes a full list of mean accuracies per sign across conditions. Appendix B includes the distribution of accuracy per semantic domain (appendices can also be found at the Open Science Framework https://osf.io/xgnhw/).

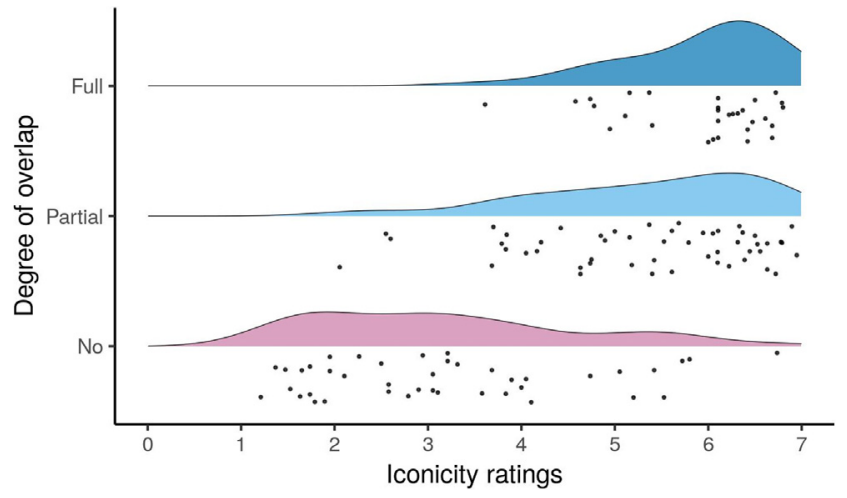

Fig. 3. Raincloud plots displaying the distribution of mean iconicity ratings of signs as a function of degree of overlap between a sign and the elicited systematic gesture (full, partial and no overlap). Wider sections of the rainclouds indicate higher concentration of data points along the iconicity axis (1: low, 7: high iconicity).

\subsubsection{Iconicity ratings}

Fig. 3 shows raincloud plots in which the data points represent individual signs distributed on the horizontal axis according to their mean iconicity ratings across participants (7-point scale where 1 and 7 represent low and high iconicity ratings, respectively). As with accuracy in guessing the meaning of signs, the plot shows a clear divide between items with no overlap $(M=3.29, S D=1.44)$, and those with partial $(M=5.29, S D=1.20)$ and full overlap $(M=5.71, S D=1.07)$. Signs with partial and full overlap with gesture cluster around the medium to high end of the scale with most items rated at 4 or higher, while those with no overlap are distributed between ratings of 1 and 4 .

The most parsimonious model for iconicity ratings consisted of random intercepts for participants and items in the random-effects structure, an interaction term of overlap with gesture (partial overlap as intercept) and degree of systematicity (i.e., proportion of participants producing the same gesture for a concept), and a main effect of semantic domain (reference $=$ action). Table 3 displays the relevant statistics and corresponding coefficients. The model reveals that signs with full overlap are rated as more iconic than those with partial overlap, while the comparison between partial and no overlap does not reach conventional significance. Further, there is a tendency to generate higher iconicity ratings when more participants produce the same systematic gesture for a concept. Let us recall that in Study 1, the concepts that elicited systematic gestures could range between 12 and 20 participants. As illustrated in Fig. 4, we find that signs in the partial overlap condition receive higher iconicity ratings when more participants produce a systematic gesture. There was no such effect for items with full or no overlap. Finally, signs for actions were rated as more iconic than signs for objects. Appendix A includes a full list of mean iconicity ratings per sign across conditions. Appendix B for a

Table 3

Estimates, standard error, and $t$-values of the main effects of the model assessing what factors significantly predict iconicity ratings of NGT signs.

\begin{tabular}{lllll}
\hline & \multicolumn{3}{l}{ Iconicity ratings } & \\
\cline { 2 - 4 } Predictor & $\beta$ & \multirow{2}{*}{$S E$} & $t$ & \multirow{2}{*}{$\operatorname{Pr}(>|t|)$} \\
\hline Intercept & 2.745 & 0.775 & 3.543 & 0.0006 \\
Overlap 0 (ref. 1) & 0.432 & 1.095 & 0.394 & 0.694 \\
Overlap 2 (ref. 1) & 3.884 & 1.373 & 2.829 & 0.005 \\
Degree systematicity & 3.607 & 0.901 & 4.005 & 0.0001 \\
Semantic domain object (ref. action) & -0.724 & 0.200 & -3.625 & 0.0004 \\
Overlap 0 * Degree systematicity & -3.004 & 1.360 & -2.209 & 0.029 \\
Overlap 2 * Degree systematicity & -4.082 & 1.626 & -2.511 & 0.013
\end{tabular}

Iconicity $\sim$ Overlap * Degree systematicity + Semantic domain $+(1 \mid$ Subject $)$ $+(1 \mid$ VIDEO). 


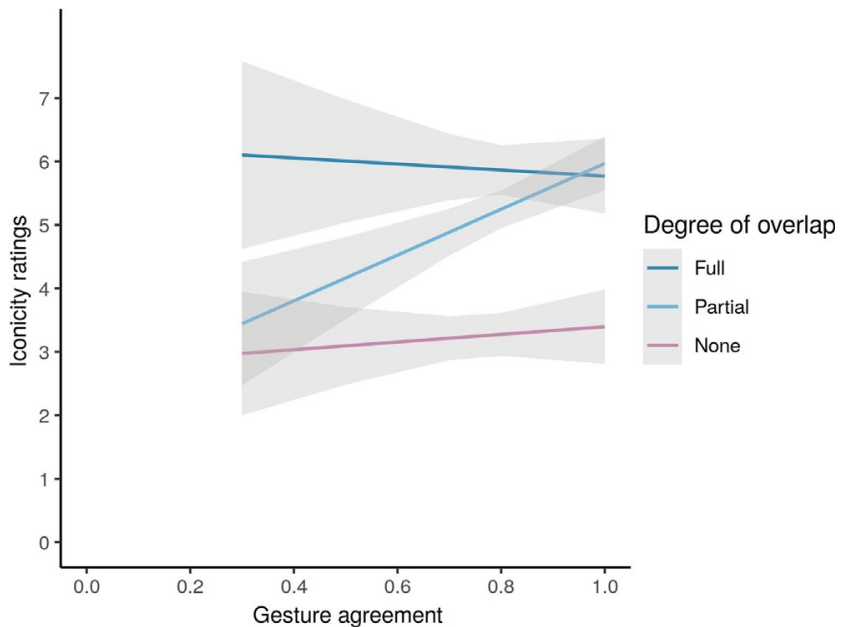

Fig. 4. Correlation of the number of participants producing a systematic gesture and iconicity ratings of signs across conditions (full, partial, and no overlap). Iconicity ratings were measured on a 7-point scale (1: low; 7: high ratings). Degree of systematicity is the proportion of participants producing the same systematic gesture. Shading represents standard errors on the iconicity ratings.

distribution of accuracy per semantic domain (https://osf.io/xgnhw/).

Finally, in order to evaluate the relationship between accuracy in guessing the meaning of signs (open-cloze) and iconicity ratings, we performed a correlation between both variables and found that they were significantly correlated $r=0.889, p<.001$ (see Fig. 5). This indicates that when non-signers accurately guess the meaning of signs they are also more likely to assign higher ratings for degree of iconicity.

\section{Discussion}

Signs and gestures may share similar iconic form-meaning mappings. In this study we investigated whether hearing adults with no experience with a sign language rely on their iconic gestures to make

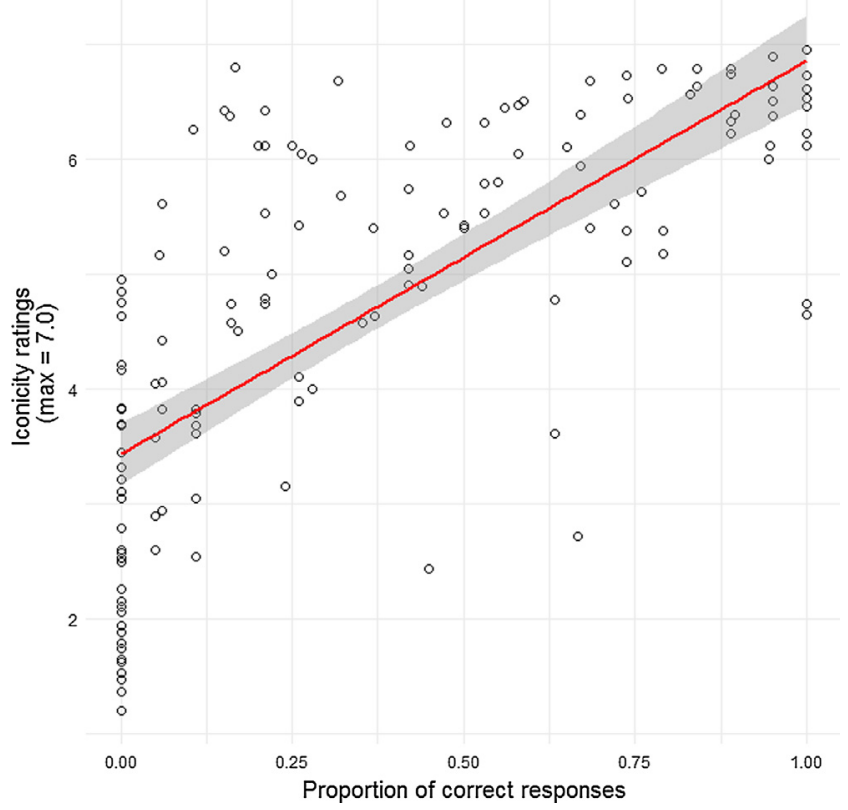

Fig. 5. Scatterplot showing the relationship between accuracy in guessing the meaning of signs and iconicity ratings. Linear regression line in red and the grey area represents the confidence region at $95 \%$. (For interpretation of the references to colour in this figure legend, the reader is referred to the web version of this article.) judgements about the meaning of signs. We predicted that non-signers could make accurate guesses about the meaning of signs and perceive them as more iconic when they had similar forms as their gestural repertoire.

After eliciting iconic silent gestures from a group of hearing nonsigning adults, we found that they have at their disposal a set of gestures that share consistent forms for some concepts. These gestures also have different degrees of similarities with the corresponding sign language equivalent (i.e., Sign Language of the Netherlands, NGT). Within our categorisation criteria and following an existing gesture notation system (Bressem, 2013), we found that non-signers' gestures may overlap completely in form with signs in their four phonological constituents (i.e., full overlap), they can differ in one phonological parameter (i.e., partial overlap) or they may be completely different in structure (i.e., no overlap). When a different group of hearing nonsigners were asked to guess the meaning of these signs and assign iconicity ratings, signs that were categorised to have full overlap with gestures were the most accurately guessed and were judged as the most iconic. In stark contrast, signs with no overlap were the least accurately guessed and received the lowest ratings. Interestingly, we found that accuracy and iconicity ratings were positively correlated with the number of participants producing a systematic gesture. Further, hearing non-signers showed a strong bias to assume that signs refer to actions and not objects. Together, these data suggest that non-signers can predict the meaning of signs never seen before and make judgements about their degree of iconicity in relation to their gestural knowledge.

\subsection{Similarities in iconic form-meaning mappings in gesture and sign}

There is a generalised assumption that the iconic strategies to represent a referent in gesture are idiosyncratic and thus variable. However, the results of the present study support recent evidence that spontaneous silent gestures may exhibit generalizable forms for many concepts across individuals (Ortega \& Özyürek, 2016, 2019; van Nispen et al., 2014). Importantly, some of these gestures overlap in form in varying degrees with conventionalised signs. This finding could be explained by deaf and hearing people sharing a conceptual substrate that skews them to produce overlapping manual structures. A central postulation of Cognitive Linguistics is that our mental conceptualizations are grounded in physical reality (Langacker, 2008). To some extent, deaf and hearing individuals living in the same community experience the world in similar ways and thus share the same mental schemas as well as the possible ways to interact with objects. As such, deaf signers and hearing gesturers converge in many sign-gesture forms because these reflect their shared mental representations that can potentially be expressed in the manual modality (e.g., the shape of a ball, the function of a key).

These similarities are the more striking when we think that signs and gestures are both expressed in the manual-visual modality. Some of the most influential scholars in gesture studies have argued that speakers' and signers' 'uses of kinesic actions are cut from the same cloth' (Kendon, 2004; p. 324) and both types of communication share more forms and functions than previously assumed (Kendon, 2004, 2008). Indeed, it has been argued that the constraints of the manualvisual modality shape language and give rise to similar structures in gesture and sign (Perniss et al., 2015). By using the same kinesic medium, signs and gestures recruit similar semiotic resources to create analogies with the body about the world around us (Müller, 2016, 2018). We argue that systematicity in gestures and across sign-gesture forms is due to individuals exploiting their shared conceptual substrate (i.e., visual, semantic, perceptual, sensorimotor representations) and expressing these representations within the physical capabilities of the body as main articulator (Sandler, 2018). 


\subsection{Gesture as gateway to the meaning of signs}

The positive effect of gesture in guessing the meaning of signs (Study 1 ) as well as iconicity ratings (Study 2 ) could be indication of the interplay of interrelated cognitive processes. It has been argued that speakers' conceptual knowledge is grounded in perceptual motor systems (Barsalou, 1999, 2008) and that the processing of concepts automatically activates motor programmes associated with them (DowningDoucet \& Guérard, 2014; Kalénine, Mirman, Middleton, \& Buxbaum, 2012; Labeye, Oker, Badard, \& Versace, 2008). Further, gestures derive from action simulations (Hostetter \& Alibali, 2008) and they largely exhibit a bias towards the acting strategy (Van Nispen et al., 2017). Therefore, it is possible that non-signers generate gestural simulations based on their motor programmes and as a result they recognise signs that match these action-based simulations.

This claim is supported by inspection of data which indicated that the full and partial overlap condition consisted of $70 \%$ and $80 \%$ of items exploiting the acting strategy; i.e., signs representing bodily actions (see Appendix A). This contrasts remarkably with signs in the no overlap condition which consisted of $30 \%$ of acting signs. It is possible that when viewing iconic signs for the first time, non-signers mainly recognised signs exploiting the acting strategy which is the most common strategy used in gesture (Ortega \& Özyürek, 2016, 2019; Van Nispen et al., 2017). For instance, after viewing a sign depicting someone stroking their head with a closed fist, non-signers recognised it and labelled it as 'combing' because the action represented (i.e., the sign TO-COMB) maps well with their own motor schema for the same concept. That is, participants perceived some of the signs as recognisable bodily actions that matched their motor schemas and thus assigned high iconicity ratings. The representation of bodily actions is therefore a point of intersection between gestures and signs, and following the notion of construal of sign iconicity (Occhino et al., 2017), deaf signers and hearing non-signers recognise these action-based manual forms because both groups share sensorimotor knowledge of these representations. These findings also relate more generally to studies showing that humans understand and evaluate others' actions through the activation of brain regions engaged when they perform the same actions themselves (Koelewijn, van Schie, Bekkering, Oostenveld, \& Jensen, 2008; Rizzolatti, Fadiga, Gallese, \& Fogassi, 1996; van Kesteren, Rijpkema, Ruiter, Morris, \& Fernandez, 2014).

The errors produced by participants clearly show that if there is a sign-gesture mismatch, sign-naïve participants are unable to accurately estimate their meaning. It may be the case that the sensory-motor features depicted in some iconic signs did not match any conceptual representations and as a result did not have any recognisable schema that could help them make an accurate guess. In some instances signs and gestures depict a different feature of the referent (e.g., the roundness of a ball vs. showing how it is manipulated) or they use different types of iconicity to represent them (e.g., tapping on a keyboard vs twojoined open palms for LAPTOP. See Fig. 1). In such cases, hearing nonsigners were less capable of matching the sign with their implicit gestural knowledge so this hindered accuracy and thus led them to assign lower iconicity ratings.

Metonymy could also explain some of the errors produced by participants. In many cases, signs do not represent exactly the concept depicted in them but rather a semantically related associate. Participants' responses often reflected that they made a direct association with the iconic elements of the sign instead of making an abstraction about it. As a result, they often produced an incorrect response which nonetheless was semantically related or visually depicted in the target. For instance, the NGT sign CURTAINS, which represents a person drawing curtains, yielded low accurate responses (15\%) with the most popular answers mainly referring to the action depicted in the sign (e.g., to close, to connect, to come together, to shut). In contrast, the sign TO-SMOKE, which represents a person bringing a cigarette to the mouth, yielded very accurate responses with only one participant out of
20 incorrectly assuming the sign referred to the object associated to the action (i.e., cigarette).

The presence of metonymy could also explain the higher performance in accuracy and ratings of signs referring to actions over objects. Participants were accurate at guessing signs referring to actions because there was a direct correspondence with the intended referent (e.g., TOSMOKE). They were less accurate at guessing signs in which the representation of an action referred to the object associated with it (e.g., CURTAINS). If we can assume that metonymy has a significant prevalence in the lexicons of all sign languages, low accuracy and iconicity ratings could be explained by gesturers' tendency to describe only what is directly encoded in signs and without making any form of semantic abstraction. This assumption could also explain low performance in earlier studies (Grosso, 1993; Klima \& Bellugi, 1979). Based on these data, it is possible to predict that at first exposure to a sign language participants will be more accurate at guessing the meaning of signs referring to actions (i.e., verbs) and less so to signs referring to objects (i.e., nouns).

An interesting finding is that degree of systematicity, that is, the number of people producing the same systematic gesture, also played a role in the accuracy and iconicity ratings of signs. This effect was particularly noticeable in signs with partial overlap with the gesture. From a construction grammar standpoint, communicative behaviours with specific meanings (e.g., vocalizations, intonation contours, gestures) can develop the status of linguistic entities because they are used on a regular basis by a community of speakers (Cienki, 2015). In our study, one could argue that certain iconic gestures may have acquired high degree of conventionalization through frequent use and thus could be stored as part of our mental representations. This would suggest that while hearing non-signers' gestural repertoire is largely variable there are some gestures which are more conventionalised than others. As such, they constitute a relatively stable repertoire shared within the community and which can assist in making form-meaning associations. These findings require further empirical scrutiny but it indicates that some gestures have more stable forms than previously assumed.

\subsection{Iconic gestures are not a silver bullet}

It must be noted that the claims made here about the relationship between sign and gesture and the extent to which gestures assist signnaïve learners to interpret the meaning of signs are based on the Dutch population and thus are not categorical statements. It may be possible that NGT has a more prominent presence of acting depictions in its lexicon and as a result there are more instances of overlap with gesture, which consists primarily of the acting strategy (Van Nispen et al., 2017). In fact there is evidence that across cultures, gesturers and signers differ in the way they represent concepts iconically (Nyst, 2016; Padden et al., 2013). While there are growing reports that second language learners of ASL and British Sign Language (BSL) recruit their gestural system at the earliest stages of acquisition (Chen Pichler, 2011; Janke \& Marshall, 2017; Marshall \& Morgan, 2015; Ortega \& Morgan, 2010) only future research comparing the iconic strategies across sign and gesture will confirm the extent to which our findings extend cross-linguistically.

Further, we observed variability in the number of participants producing the same gesture (range: 12-20), many concepts failed to elicit a systematic gesture ( $n=127$ concepts), and there was no overlap with many signs ( $\mathrm{n}=55$ signs). Also, while signs are lexical entries in signers' lexicon (e.g., Carreiras, Gutiérrez-Sigut, Baquero, \& Corina, 2008), silent gestures are spontaneous creations that stem from the selection of salient features of the referent and expressing them with the hands (Goldin-Meadow \& Brentari, 2017; Van Nispen et al., 2017). It is undeniable that signs and gestures have important differences in terms of constitution, processing, and degree of conventionalization. However, the argument we want to put forward is that despite their intrinsic differences there is growing evidence that many gestures and signs recruit the same semiotic resources to depict referents iconically 
(Kendon, 2008; Müller, 2018). As a result, they often capture the same feature of a referent and depict it in remarkably similar ways. These similarities are unique to the manual-visual modality and reveal important insights regarding the relationship between gesture and sign, as well as the similarities in the signed lexicons around the world.

\subsection{Implications}

The overlap in form and meaning between signs and gestures has important implications in the acquisition of a sign language as a second language (L2) by hearing adults. One of the most important steps in vocabulary learning is the linking of a phonological form with its meaning (Barcroft, 2015; Nation, 2001) and to a great extent the presence of cognates, native words that resemble an L2 target, alleviates this cognitively demanding task (Hall, 2002; Peeters, Dijkstra, \& Grainger, 2013). Some have argued that the modality differences between speech and sign do not allow for cross-linguistic influence and as such learners cannot rely on their first language to assist them in vocabulary learning (Chen Pichler, 2011). The label L2M2 has been put forward to suggest that sign L2 learners are not only acquiring a second language (L2) but they are also developing experience with a new (manual) modality (M2) (Chen Pichler, 2011). However, despite the modality differences between speech and sign, our data clearly show that learners fall back on their gestures to facilitate making signmeaning associations. As such we argue that non-signers' gestural repertoire acts as some sort of 'manual cognates' that allows them to scaffold their developing manual lexicon.

\section{Conclusion}

The language and psychological sciences are trying to unravel the mechanism that allow individuals to make form-meaning associations with iconic structures in all modalities of language (e.g., Occhino et al., 2017; Perlman \& Lupyan, 2018; Sidhu \& Pexman, 2017). Here we argue that hearing non-signers can make links between a novel sign and its meaning by exploiting their gestural system. Our findings speak in favour of theories claiming that gesture and sign share important similarities due to the physical constraints of the manual-visual modality (Ferrara \& Hodge, 2018; Kendon, 2004, 2008; Perniss et al., 2015). We acknowledge that interpretation of sign iconicity rests on a personal construal that 'cannot be measured via truth-conditions' (Occhino et al., 2017; p. 5), but we go beyond by arguing that hearing gesturers and deaf signers share a conceptual substrate about how certain concepts are represented in the manual modality. These similarities are exploited by hearing non-signers as gateway to the meaning of signs never seen before. Future research will gain insight on this shared conceptual substrate by investigating form-meaning mappings in deaf signers and hearing gesturers across different cultures.

\section{Acknowledgments}

This work has been supported by a Veni grant awarded by the Netherlands Organisation for Scientific Research to the first author (grant number 275-89-021). We would like to thank Anita Slonimska and Swen Schreiter who helped with data collection, coding and classification of gestures and signs. We would also like to express our gratitude to the deaf informants who guided us on the lexicon of Sign Language of the Netherlands, and who served as model for the stimulus materials. We would also like to express our gratitude to Francie Manhardt and Bodo Winter for their support and guidance in the statistical analysis (errors are our own).

Appendix A. . Mean iconicity ratings range 1 (low) - 7 (high). Modes of representation: acting, drawing, representing (Müller, 2013), and personification (Hwang et al., 2016)

\begin{tabular}{|c|c|c|c|c|}
\hline & \multicolumn{4}{|c|}{ Full overlap $(\mathrm{N}=36)$} \\
\hline 1 & BABY & baby & acting & 6.39 \\
\hline 3 & BICYCLE & fiets & acting & 6.47 \\
\hline 4 & BIRD & vogel & personification & 6.45 \\
\hline 5 & BOOK & boek & representing & 6.68 \\
\hline 6 & CALCULATOR & rekenmachine & acting & 4.78 \\
\hline 9 & HELICOPTER & helikopter & drawing & 4.58 \\
\hline 10 & KEY & sleutel & acting & 6.26 \\
\hline 11 & PIANO & piano & acting & 6.05 \\
\hline 12 & SPIDER & spin & representing & 4.65 \\
\hline 13 & SPOON & lepel & acting & 5.37 \\
\hline 14 & STAIRS & trap & representing & 5.40 \\
\hline 15 & SUITCASE & koffer & acting & 3.61 \\
\hline 21 & TO-GO-UP & omhoog lopen & representing & 2.44 \\
\hline 22 & TO-IRON & strijken & acting & 6.42 \\
\hline 23 & TO-JOG & joggen & acting & 6.11 \\
\hline 24 & TO-LISTEN & luisteren & acting & 6.50 \\
\hline 25 & TO-PHONE & bellen & representing & 6.72 \\
\hline 26 & TO-PUMP & oppompen & acting & 5.16 \\
\hline 27 & TO-ROW & roeien & acting & 6.32 \\
\hline 28 & TO-RUN & rennen & acting & 6.11 \\
\hline 29 & TO-SKI & skien & acting & 4.95 \\
\hline 30 & TO-SLAP & slaan & acting & 6.11 \\
\hline 31 & TO-SLEEP & slapen & acting & 6.80 \\
\hline 32 & TO-SWIM & zwemmen & acting & 6.11 \\
\hline
\end{tabular}




\begin{tabular}{|c|c|c|c|c|}
\hline 33 & TO-WALK & lopen & representing & 6.37 \\
\hline 34 & TO-WAVE & uitzwaaien & acting & 6.42 \\
\hline 35 & TOWEL & handdoek & acting & 5.11 \\
\hline \multirow[t]{3}{*}{36} & TO-WRING & wringen & acting & 6.11 \\
\hline & & & Mean & 5.71 \\
\hline & & & SD & 1.07 \\
\hline
\end{tabular}

\begin{tabular}{|c|c|c|c|c|c|}
\hline & \multicolumn{5}{|l|}{ Partial overlap $(\mathrm{N}=54)$} \\
\hline & English gloss & Dutch gloss & Iconicity rating & Mode of representation & Differing parameter \\
\hline 1 & ACCORDION & accordeon & 6.95 & acting & handshape \\
\hline 2 & APPLE & appel & 2.55 & acting & handshape \\
\hline 3 & BLANKET & deken & 3.79 & acting & handshape \\
\hline 4 & BRIDGE & brug & 4.63 & drawing & handshape \\
\hline 5 & CELL & gevangenis & 3.84 & acting & movement \\
\hline 6 & CURTAINS & gordijnen & 4.74 & acting & movement \\
\hline 7 & DEER & hert & 4.58 & personification & handshape \\
\hline 8 & DRILL & boor & 3.83 & acting & handshape \\
\hline 9 & GUITAR & gitaar & 6.72 & acting & handshape \\
\hline 10 & HOUSE & huis & 4.63 & drawing & handshape \\
\hline 11 & ICE-CREAM & ijsje & 6.32 & acting & movement \\
\hline 12 & KIWI & kiwi & 2.06 & acting & handshape \\
\hline 13 & LIGHTER & aansteker & 4.89 & acting & movement \\
\hline 14 & LOBSTER & kreeft & 3.45 & personification & handshape \\
\hline 15 & MILK & melk & 2.60 & acting & handshape \\
\hline 16 & MONKEY & aap & 4.50 & acting & location \\
\hline 17 & MOTORBIKE & brommer & 6.22 & acting & movement \\
\hline 18 & PISTOL & pistool & 5.61 & representing & handshape \\
\hline 19 & PYRAMID & piramide & 6.00 & representing & movement \\
\hline 20 & RATTLE & rammelaar & 4.75 & acting & handshape \\
\hline 21 & SCREWDRIVER & schroevendraaier & 5.68 & acting & handshape \\
\hline 22 & SNAKE & slang & 5.74 & representing & handshape \\
\hline 23 & TEA & thee & 5.53 & acting & handshape \\
\hline 24 & TO-СОМВ & kammen & 6.37 & acting & handshape \\
\hline 25 & TO-CRASH & botsen & 5.79 & representing & handshape \\
\hline 26 & TO-DRINK & drinken & 6.63 & acting & movement \\
\hline 27 & TO-ERASE & uitgummen & 4.21 & acting & orientation \\
\hline 28 & TO-HAMMER & hameren & 6.05 & acting & handshape \\
\hline 29 & TO-INJECT & injecteren & 6.11 & acting & handshape \\
\hline 30 & TO-ITCH & krabben & 6.53 & acting & location \\
\hline 31 & TO-JUGGLE & jongleren & 5.42 & acting & handshape \\
\hline 32 & TO-KNEAD & kneden & 5.00 & acting & handshape \\
\hline 33 & TO-KNOCK & kloppen & 6.10 & acting & handshape \\
\hline 34 & TO-KNOW & weten & 5.61 & deictic & movement \\
\hline 35 & TOOTHBRUSH & tandenborstel & 3.68 & acting & handshape \\
\hline 36 & TO-POWDER & poederen & 6.44 & acting & handshape \\
\hline 37 & TO-PRAY & bidden & 5.94 & acting & handshape \\
\hline 38 & TO-PULL & trekken & 6.10 & acting & handshape \\
\hline 39 & TO-SAW & zagen & 6.79 & acting & handshape \\
\hline 40 & TO-SHAVE & scheren & 5.18 & acting & handshape \\
\hline 41 & TO-SMOKE & roken & 6.78 & acting & handshape \\
\hline 42 & TO-SMS & sms'en & 4.17 & acting & movement \\
\hline 43 & TO-SPEAK & praten & 6.39 & representing & location \\
\hline 44 & TO-STAPLE & nieten & 4.85 & acting & handshape \\
\hline 45 & TO-STINK & stinken & 6.56 & acting & handshape \\
\hline 46 & TO-TAKE-РНОTO & fotograferen & 6.33 & acting & handshape \\
\hline 47 & TO-TOAST & proosten & 5.16 & acting & handshape \\
\hline 48 & TO-WATCH & kijken & 5.37 & acting & movement \\
\hline 49 & TO-WRITE & schrijven & 6.50 & acting & handshape \\
\hline 50 & UMBRELLA & paraplu & 5.40 & acting & movement \\
\hline 51 & VIOLIN & viool & 6.89 & acting & handshape \\
\hline 52 & WHEELCHAIR & rolstoel & 4.05 & acting & handshape \\
\hline 53 & WINDSCREEN-WIPER & ruitenwisser & 6.63 & representing & handshape \\
\hline \multirow[t]{3}{*}{54} & ZIMMER & rollator & 4.42 & acting & handshape \\
\hline & & Mean & 5.32 & & \\
\hline & & SD & 1.19 & & \\
\hline
\end{tabular}

\begin{tabular}{|c|c|c|c|c|}
\hline & \multicolumn{4}{|c|}{ No overlap $(\mathrm{N}=55)$} \\
\hline & English gloss & Dutch gloss & Mode of representation & Iconicity rating \\
\hline 1 & BALL & bal & drawing & 4.05 \\
\hline 2 & BATH & bad & acting & 2.58 \\
\hline
\end{tabular}




\begin{tabular}{|c|c|}
\hline BED & bed \\
\hline BEER & bier \\
\hline BOTTLE & fles \\
\hline BOX & doos \\
\hline BUILDING & gebouw \\
\hline BUTTERFLY & vlinder \\
\hline BUS & bus \\
\hline CAT & kat \\
\hline CHICKEN & kip \\
\hline COFFEE & koffie \\
\hline DOCTOR & dokter \\
\hline DOOR & deur \\
\hline EAGLE & adelaar \\
\hline ELECTRICITY & elektriciteit \\
\hline ELEPHANT & olifant \\
\hline FLOWER & bloem \\
\hline FRUIT & fruit \\
\hline HORSE & paard \\
\hline LAPTOP & laptop \\
\hline LIGHTBULB & gloeilamp \\
\hline MUSHROOM & champignon \\
\hline PENGUIN & pinguin \\
\hline PERSON & persoon \\
\hline PLANE & vliegtuig \\
\hline PRAM & buggy \\
\hline PUPPET & pop \\
\hline RABBIT & konijn \\
\hline RACKET & tennis racket \\
\hline RESTAURANT & restaurant \\
\hline SALT & zout \\
\hline SHEEP & schaap \\
\hline SNAIL & slak \\
\hline SUGAR & suiker \\
\hline TO-ARGUE & ruzie maken \\
\hline TO-COOK & koken \\
\hline TO-CRY & huilen \\
\hline TO-CUT (knife) & snijden \\
\hline TO-DIE & overlijden \\
\hline TO-FLY (plane) & vliegen \\
\hline TO-GO-OUT & uitgaan \\
\hline TO-GOSSIP & roddelen \\
\hline TO-PARK & parkeren \\
\hline TO-PUT-CLOTHES-ON & aankleden \\
\hline TO-RELAX & ontspannen \\
\hline TO-SAY & zeggen \\
\hline TO-SHOUT & scheeuwen \\
\hline TO-SIGN & gebaren \\
\hline TO-SIT & zitten \\
\hline TO-STEAL & stelen \\
\hline TREE & boom \\
\hline TURTLE & schildpad \\
\hline WATER & water \\
\hline WOMAN & vrouw \\
\hline
\end{tabular}

\begin{tabular}{|c|c|}
\hline acting & 3.21 \\
\hline acting & 5.72 \\
\hline drawing & 3.68 \\
\hline drawing & 5.05 \\
\hline drawing & 1.63 \\
\hline representing & 5.94 \\
\hline drawing & 1.74 \\
\hline personification & 3.61 \\
\hline personification & 3.83 \\
\hline acting & 2.90 \\
\hline arbitrary & 1.74 \\
\hline representing & 4.00 \\
\hline personification & 5.53 \\
\hline arbitrary & 1.79 \\
\hline personification & 6.53 \\
\hline acting & 3.11 \\
\hline arbitrary & 1.47 \\
\hline acting & 1.63 \\
\hline representing & 5.42 \\
\hline acting & 1.21 \\
\hline representing & 3.05 \\
\hline personification & 4.79 \\
\hline drawing & 2.53 \\
\hline representing & 4.11 \\
\hline acting & 1.74 \\
\hline acting & 1.53 \\
\hline personification & 3.16 \\
\hline acting & 3.83 \\
\hline representing & 3.21 \\
\hline acting & 4.74 \\
\hline acting & 2.16 \\
\hline representing & 4.90 \\
\hline arbitrary & 1.37 \\
\hline arbitrary & 2.94 \\
\hline representing & 2.11 \\
\hline representing & 6.74 \\
\hline representing & 5.53 \\
\hline arbitrary & 2.50 \\
\hline representing & 5.80 \\
\hline arbitrary & 1.89 \\
\hline arbitrary & 1.95 \\
\hline representing & 3.89 \\
\hline acting & 3.32 \\
\hline arbitrary & 2.50 \\
\hline representing & 3.58 \\
\hline representing & 2.79 \\
\hline acting & 3.05 \\
\hline arbitrary & 1.95 \\
\hline acting & 5.20 \\
\hline drawing & 2.26 \\
\hline representing & 4.06 \\
\hline arbitrary & 1.65 \\
\hline ting & 2.60 \\
\hline ean & 3.34 \\
\hline & 1.47 \\
\hline
\end{tabular}

Appendix B. . Mean iconicity ratings and proportion of accurate responses across conditions (i.e., full, partial, no overlap) and semantic domain

Mean iconicity ratings and mean proportion of correct responses according to overlap with the NGT sign (full, partial, no overlap) and per semantic domain

Mean iconicity rating was measured on a 7-point scale (1: low, 7: high)

The mean accuracy is the average of all items within each type of sign-gesture overlap so it does not add to 100 .

\begin{tabular}{|c|c|c|c|c|c|c|c|c|c|c|}
\hline & \multicolumn{2}{|c|}{ Actions with object $(\mathrm{N}=29)$} & \multicolumn{2}{|c|}{$\begin{array}{l}\text { Actions without object } \\
(\mathrm{N}=30)\end{array}$} & \multicolumn{2}{|c|}{ Animate entities $(\mathrm{N}=22)$} & \multicolumn{2}{|c|}{ Manipulable objects $(\mathrm{N}=41)$} & \multicolumn{2}{|c|}{$\begin{array}{l}\text { Non-manipulable objects } \\
(\mathrm{N}=24)\end{array}$} \\
\hline & $\begin{array}{l}\text { Iconicity } \\
\text { rating }\end{array}$ & $\begin{array}{l}\text { Mean accu- } \\
\text { racy }\end{array}$ & $\begin{array}{l}\text { Iconicity } \\
\text { rating }\end{array}$ & $\begin{array}{l}\text { Mean accu- } \\
\text { racy }\end{array}$ & $\begin{array}{l}\text { Iconicity } \\
\text { rating }\end{array}$ & $\begin{array}{l}\text { Mean accu- } \\
\text { racy }\end{array}$ & $\begin{array}{l}\text { Iconicity } \\
\text { rating }\end{array}$ & $\begin{array}{l}\text { Mean accu- } \\
\text { racy }\end{array}$ & $\begin{array}{l}\text { Iconicity } \\
\text { rating }\end{array}$ & $\begin{array}{l}\text { Mean accu- } \\
\text { racy }\end{array}$ \\
\hline Full overlap & 6.3 & 0.72 & 6.21 & 0.66 & 5.72 & 0.38 & 5.5 & 0.43 & 5.45 & 0.45 \\
\hline $\begin{array}{l}\text { Partial overl- } \\
\text { ap }\end{array}$ & 5.77 & 0.55 & 6.19 & 0.65 & 4.84 & 0.65 & 4.9 & 0.39 & 4.78 & 0.3 \\
\hline No overlap & 4.48 & 0.22 & 3.15 & 0.13 & 3.62 & 0.13 & 3.16 & 0.09 & 2.83 & 0.1 \\
\hline
\end{tabular}


Appendix C. . Concepts that did not elicit a systematic gesture

\begin{tabular}{|c|c|c|}
\hline & English & Dutch \\
\hline 1 & AMBULANCE & AMBULANCE \\
\hline 2 & AVOCADO & AVOCADO \\
\hline 3 & BATH & BAD \\
\hline 4 & BEAR & BEER \\
\hline 5 & BELT & RIEM \\
\hline 6 & BINOCULARS & VERREKIJKER \\
\hline 7 & BITE & HAPJE \\
\hline 8 & BLANKET & DEKEN \\
\hline 9 & BLENDER & BLENDER \\
\hline 10 & BOAT & ВоОт \\
\hline 11 & BOOKSHELF & BOEKENPLANK \\
\hline 12 & BOTERHAM & BOTERHAM \\
\hline 13 & BREAD & BROOD \\
\hline 14 & BUS & BUS \\
\hline 15 & BUTTERFLY & VLINDER \\
\hline 16 & CAT & КАТ \\
\hline 17 & CHICKEN & KIP \\
\hline 18 & CHILD & KIND \\
\hline 19 & CLOCK & KLOK \\
\hline 20 & COCONUT & KOKOSNOOT \\
\hline 21 & COFFEE & KOFFIE \\
\hline 22 & cow & KOE \\
\hline 23 & COWBOY & COWBOY \\
\hline 24 & CRUTCHES & KRUKKEN \\
\hline 25 & DOCTOR & DOKTER \\
\hline 26 & DOG & HOND \\
\hline 27 & DROPS & DRUPPELS \\
\hline 28 & DUCK & EEND \\
\hline 29 & EAGLE & ADELAAR \\
\hline 30 & ELECTRICITY & ELEKTRICITEIT \\
\hline 31 & ELEPHANT & OLIFANT \\
\hline 32 & FIRE & VUUR \\
\hline 33 & FLOOR & VERDIEPING \\
\hline 34 & FLOWER & BLOEM \\
\hline 35 & FOX & vos \\
\hline 36 & FROG & KIKKER \\
\hline 37 & FRUIT & FRUIT \\
\hline 38 & GIRAFFE & GIRAF \\
\hline 39 & GOAT & GEIT \\
\hline 40 & HAIR & HAAR \\
\hline 41 & HAT & HOED \\
\hline 42 & HIPPO & NIJLPAARD \\
\hline 43 & HORSE & PAARD \\
\hline 44 & INTERPRETER & TOLK \\
\hline 45 & IPAD & IPAD \\
\hline 46 & IPHONE & IPHONE \\
\hline 47 & JACKET & JAS \\
\hline 48 & KIWI & KIWI \\
\hline 49 & LIGHTBULB & GLOEILAMP \\
\hline 50 & LION & LEEUW \\
\hline 51 & MILK & MELK \\
\hline 52 & MOSQUITO & MUG \\
\hline 53 & MUMMY & MAMA \\
\hline 54 & MUSHROOM & CHAMPIGNON \\
\hline 55 & MUSIC & MUZIEK \\
\hline 56 & ORANGE & SINAASAPPEL \\
\hline 57 & OWL & UIL \\
\hline 58 & PEPPER & PEPER \\
\hline 59 & PERSON & PERSOON \\
\hline 60 & PIG & VARKEN \\
\hline 61 & PILLOW & HET KUSSEN \\
\hline 62 & PLANE & VLIEGTUIG \\
\hline 63 & PLASTER-CAST & GIPS \\
\hline 64 & POLICE OFFICER & POLITIEAGENT \\
\hline 65 & PUPPET & POP \\
\hline 66 & RABBIT & KONIJN \\
\hline 67 & RESTAURANT & RESTAURANT \\
\hline 68 & RHINO & NEUSHOORN \\
\hline 69 & ROOM & KAMER \\
\hline 70 & ROOSTER & HAAN \\
\hline 71 & SANDWICH & TOSTI \\
\hline 72 & SAXOPHONE & SAXOFOON \\
\hline 73 & SEAHORSE & ZEEPAARD \\
\hline 74 & SEAL & ZEEHOND \\
\hline 75 & SHEEP & SCHAAP \\
\hline 76 & SKUNK & STINKDIER \\
\hline
\end{tabular}




\begin{tabular}{|c|c|c|}
\hline 77 & SNAIL & SLAK \\
\hline 78 & SOAP & ZEEP \\
\hline 79 & SOFA & SOFA \\
\hline 80 & SPREADABLE CHEESE & SMEERKAAS \\
\hline 81 & SQUIRREL & EEKHOORN \\
\hline 82 & SUBWAY & METRO \\
\hline 83 & SUGAR & SUIKER \\
\hline 84 & SUN & ZON \\
\hline 85 & TABLE & TAFEL \\
\hline 86 & TIE & STROPDAS \\
\hline 87 & TO-ARGUE & RUZIE MAKEN \\
\hline 88 & TO-BLOW & BLAZEN \\
\hline 89 & TO-BREATHE & INADEMEN \\
\hline 90 & TO-BREATHE & ADEMHALEN \\
\hline 91 & TO-BUY & KOPEN \\
\hline 92 & TO-CARRY & DRAGEN \\
\hline 93 & TO-САТСH & VANGEN \\
\hline 94 & TO-COME & KOMMEN \\
\hline 95 & TO-COOK & KOKEN \\
\hline 96 & TO-COUGH & HOESTEN \\
\hline 97 & TO-CRAWL & KRUIPEN \\
\hline 98 & TO-CROSS-FINGERS & DUIMEN \\
\hline 99 & TO-DIE & OVERLIJDEN \\
\hline 100 & TO-DRY & AFDROGEN \\
\hline 101 & TO-DUST & AFSTOFFEN \\
\hline 102 & TO-EAT & ETEN \\
\hline 103 & TO-FAINT & FLAUWALLEN \\
\hline 104 & TO-FISH & VISSEN \\
\hline 105 & TO-FOLD & VOUWEN \\
\hline 106 & TO-GESTURE-COME & WENKEN \\
\hline 107 & TO-GIVE & GEVEN \\
\hline 108 & TO-GO-OUT & UITGAAN \\
\hline 109 & TO-GOSSIP & RODDELEN \\
\hline 110 & TO-GRAB & PAKKEN \\
\hline 111 & TO-HOOVER & STOFZUIGEN \\
\hline 112 & TO-HUG & KNUFFELEN \\
\hline 113 & TOILET & TOILET \\
\hline 114 & TO-INSERT-BEADS & RIGJEN \\
\hline 115 & TO-JOG & JOGGEN \\
\hline 116 & TO-KICK & SCHOPPEN \\
\hline 117 & TO-KISS & KUSSEN \\
\hline 118 & TO-KNIT & BREIEN \\
\hline 119 & TO-LAUGH & LACHEN \\
\hline 120 & TO-LIFT & OPTILLEN \\
\hline 121 & TO-LOVE & HOUDE VAN \\
\hline 122 & TO-MASSAGE & MASSEREN \\
\hline 123 & TO-MEET & ONTMOETEN \\
\hline 124 & TO-OPEN & OPENEN \\
\hline 125 & TO-ORDER & BESTELLEN \\
\hline 126 & TOOTHBRUSH & TANDENBORSTEL \\
\hline 127 & TO-PARK & PARKEREN \\
\hline 128 & TO-PEEL (knife) & SCHILLEN \\
\hline 129 & TO-PICK-UP & OPHALEN \\
\hline 130 & TO-PLAY-CARDS & KAARTEN \\
\hline 131 & TO-PLAY-POOL & POOLEN \\
\hline 132 & TO-POUR & GIETEN \\
\hline 133 & TO-PUT-CLOTHES-ON & AANKLEDEN \\
\hline 134 & TO-RAIN & REGENEN \\
\hline 135 & TO-READ & LEZEN \\
\hline 136 & TO-RELAX & ONTSPANNEN \\
\hline 137 & TO-ROLL & ROLLEN \\
\hline 138 & TO-RUN & RENNEN \\
\hline 139 & TO-SAY & ZEGGEN \\
\hline 140 & TO-SEE & ZIEN \\
\hline 141 & TO-SIEVE & FLOUR \\
\hline 142 & TO-SIGN & GEBAREN \\
\hline 143 & TO-SIT & ZITTEN \\
\hline 144 & TO-SOAP & INZEPEN \\
\hline 145 & TO-SPRAY & BESPROEIEN \\
\hline 146 & TO-STAND & STAAN \\
\hline 147 & TO-STAPLE & NIETEN \\
\hline 148 & TO-STEAL & STELEN \\
\hline 149 & TO-STINK & STINKDIER \\
\hline 150 & TO-TAKE-SHOWER & DOUCHEN \\
\hline
\end{tabular}


Appendix D. . Still images of the examples in sign language of the Netherlands (NGT) discussed in the manuscript

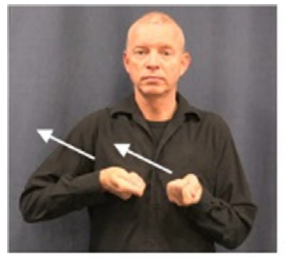

TO-PULL

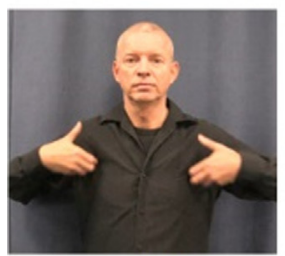

MONKEY

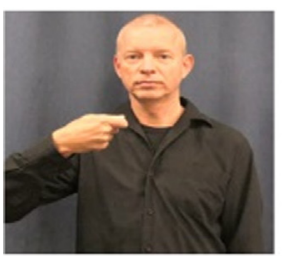

SPOON

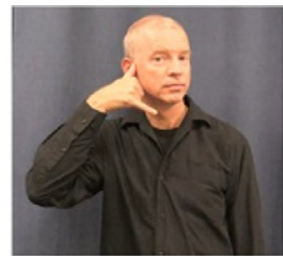

TO-PHONE

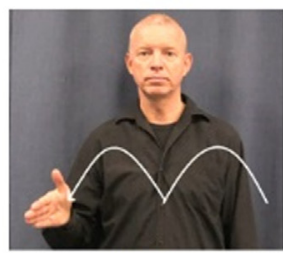

CAMEL

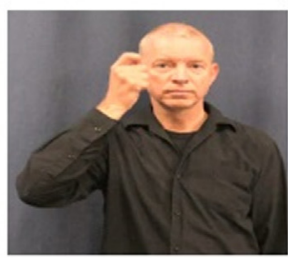

TO-COMB

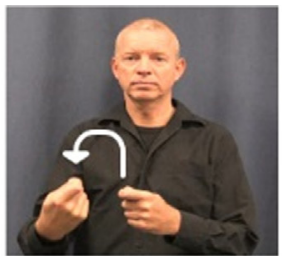

BANANA

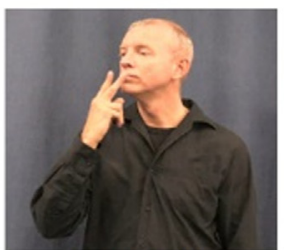

TO-SMOKE

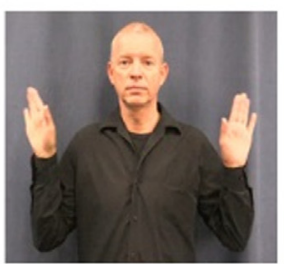

BIRD

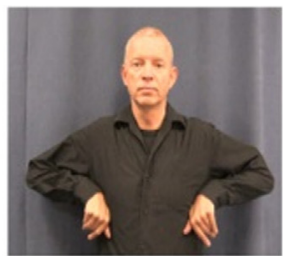

DUCK

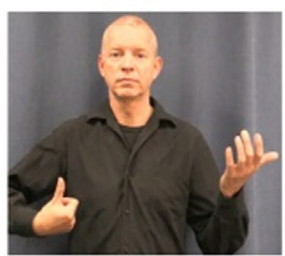

GUITAR

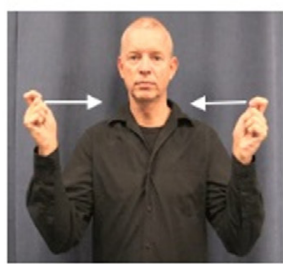

CURTAINS

\section{Appendix E. Supplementary data}

Supplementary data to this article can be found online at https://doi.org/10.1016/j.cognition.2019.06.008.

\section{References}

Baayen, H., Davidson, D., \& Bates, D. (2008). Mixed-effects modeling with crossed random effects for subjects and items. Journal of Memory and Language, 59, 390-412.

Barcroft, J. (2015). Lexical input processing and vocabulary learning. Amsterdam: John Benjamins Publishing Company.

Barsalou, L. W. (1999). Perceptual symbol systems. Behavioral and Brain Sciences, 22(4), 577-609. https://doi.org/10.1017/S0140525X99252144.

Barsalou, L. W. (2008). Grounding symbolic operations in the brain's modal systems. In G. Semin, \& E. Smith (Eds.). Embodied Grounding. Social, cognitive, affective and neuroscientific approaches (pp. 9-42). Cambridge: Cambridge University Press.

Bates, D., Maechler, M., Bolker, B, \& Walker, S. (2015). Fitting Linear Mixed-Effects Models Using lme4. Journal of Statistical Software. Journal of Statistical Software, 67(1), 1-48.

Baus, C., Carreiras, M., \& Emmorey, K. (2012). When does iconicity in sign language matter? Language and Cognitive Processes, 28(3), 261-271. https://doi.org/10.1016/j. cognition.2008.05.012.

Brentari, D. (1999). A prosodic model of sign language phonology. Cambridge: MIT Press. Brentari, D., Renzo, A. Di, Keane, J., \& Volterra, V. (2015). Cognitive, cultural, and linguistic sources of a handshape distinction expressing agentivity. Topics in Cognitive Science, 7(1), 95-123. https://doi.org/10.1111/tops.12123.

Bressem, J. (2013). A linguistic perspective on the notation of form features in gesture. In C. Muller, A. Cienki, E. Fricke, S. Ladewig, D. McNeill, \& S. Tessendorf (Eds.), Body Language - Communication: An International Handbook on Multimodality in Human Interaction (pp. 1079-1098). De Gruyter Mouton.

Campbell, R., Martin, P., \& White, T. (1992). Forced choice recognition of sign in novice learners of British Sign Language. Applied Psycholinguistics, 13(2), 185-201. https:// doi.org/10.1093/applin/13.2.185.

Carreiras, M., Gutiérrez-Sigut, E., Baquero, S., \& Corina, D. (2008). Lexical processing in Spanish Sign Language (LSE). Journal of Memory and Language, 58(1), 100-122. https://doi.org/10.1016/j.jml.2007.05.004.

Chen Pichler, D. (2011). Sources of handshape error in first-time signers of ASL. In G. Mathur, \& D. J. Napoli (Eds.). Deaf Around the World: The Impact of Language (pp. 96126). Oxford: Oxford University Press.

Christensen, P., Fusaroli, R., \& Tylén, K. (2016). Environmental constraints shaping constituent order in emerging communication systems: Structural iconicity, interactive alignment and conventionalization. Cognition, 146, 67-80. https://doi.org/10. 1016/j.cognition.2015.09.004.

Cienki, A. (2015). Spoken language usage events. Language and Cognition, 7(04), 499-514. https://doi.org/10.1017/langcog.2015.20.

Cook, S. W., \& Tanenhaus, M. K. (2009). Embodied communication: Speakers' gestures affect listeners' actions. Cognition, 113(1), 98-104. https://doi.org/10.1016/j. cognition.2009.06.006.

Cuxac, C. (1999). The expression of spatial relations and the spatialization of semantic relations in French Sign Languag. In C. Fuchs, \& S. Robert (Eds.). Language diversity and cognitive representations (pp. 123-142). Amsterdam: John Benjamins Publishing Company.

de Ruiter, J. P. (2007). Postcards from the mind: The relationship between speech, imagistic gesture, and thought. Gesture, 7(1), 21-38. https://doi.org/10.1075/gest.7. 1.03rui.

Dingemanse, M., Blasi, D. E., Lupyan, G., Christiansen, M. H., \& Monaghan, P. (2015). Arbitrariness, iconicity and systematicity in language. Trends in Cognitive Sciences, 19(10), 603-615. https://doi.org/10.1016/j.tics.2015.07.013.

Downing-Doucet, F., \& Guérard, K. (2014). A motor similarity effect in object memory. Psychonomic Bulletin and Review, 21(4), 1033-1040. https://doi.org/10.3758/ s13423-013-0570-5.

Drijvers, L., \& Ozyürek, A. (2017). Visual context enhanced: The joint contribution of iconic gestures and visible speech to degraded speech comprehension. Journal of Speech, Language, and Hearing Research, 60(January), 212-222. https://doi.org/10. 1044/2016.

Emmorey, K. (2014). Iconicity as structure mapping. Philosophical Transactions of the Royal Society of London. Series B, Biological Sciences, 369(20130301).

Ferrara, L., \& Hodge, G. (2018). Language as description, indication, and depiction. Frontiers in Psychology, 9(May), 1-15. https://doi.org/10.3389/fpsyg.2018.00716.

Gibson, E., Piantadosi, S. T., Brink, K., Bergen, L., Lim, E., \& Saxe, R. (2013). A noisychannel account of crosslinguistic word-order variation. Psychological Science, 24(7), 1079-1088. https://doi.org/10.1177/0956797612463705.

Goldin-Meadow, S., \& Brentari, D. (2017). Gesture, sign and language: The coming of age of sign language and gesture studies. Behavioral and Brain Sciences, (November), 1-59. 10.1017/S0140525X15001247.

Goldin-Meadow, S., McNeill, D., \& Singleton, J. (1996). Silence is liberating: Removing the handcuffs on grammatical expression in the manual modality. Psychological Review, 103(1), 34-55. https://doi.org/10.1037/0033-295X.103.1.34.

Goldin-Meadow, S., So, W. C., Ozyürek, A., \& Mylander, C. (2008). The natural order of events: How speakers of different languages represent events nonverbally. Proceedings 
of the National Academy of Sciences of the United States of America, 105(27), 9163-9168. https://doi.org/10.1073/pnas.0710060105.

Griffith, P. L., Robinson, J. H., \& Panagos, J. M. (1981). Perception of iconicity in American sign language by hearing and deaf subjects. The Journal of Speech and Hearing Disorders, 46(4), 388-397. https://doi.org/10.1044/jshd.4604.388.

Grosso, B. (1993). Iconicity and arbitrariness in Italian sign language: An experimental study. Italy: University of Padua.

Gunter, T. C., \& Bach, P. (2004). Communicating hands: ERPs elicited by meaningful symbolic hand postures. Neuroscience Letters, 372(1), 52-56.

Hall, C. (2002). The automatic cognate form assumption: Evidence for the parasitic model of vocabulary development. International Review of Applied Linguistics in Language Teaching, 40(2), 69-86.

Hall, M. L., Mayberry, R. I., \& Ferreira, V. S. (2013). Cognitive constraints on constituent order: Evidence from elicited pantomime. Cognition, 129(1), 1-17. https://doi.org/ 10.1016/j.cognition.2013.05.004.

Hostetter, A. B., \& Alibali, M. W. (2008). Visible embodiment: Gestures as simulated action. Psychonomic Bulletin \& Review, 15(3), 495-514. https://doi.org/10.3758/PBR. 15.3.495.

Hwang, S.-O., Tomita, N., Morgan, H., Ergin, R., Ilkbasaran, D., Seegers, S., ... Padden, C. (2016). Of the body and the hands: Patterned iconicity for semantic categories. Language and Cognition, 1-30. https://doi.org/10.1017/langcog.2016.28.

Janke, V., \& Marshall, C. R. (2017). Using the hands to represent objects in space: Gesture as a substrate for signed language acquisition. Frontiers in Psychology, 8(NOV), 1-13. https://doi.org/10.3389/fpsyg.2017.02007.

Kalénine, S., Mirman, D., Middleton, E. L., \& Buxbaum, L. J. (2012). Temporal dynamics of activation of thematic and functional knowledge during conceptual processing of manipulable artifacts. Journal of Experimental Psychology: Learning Memory and Cognition, 38(5), 1274-1295. https://doi.org/10.1037/a0027626.

Kelly, S. D., Özyürek, A., \& Maris, E. (2010). Two sides of the same coin: Speech and gesture mutually interact to enhance comprehension. Psychological Science, 21(2), 260-267. https://doi.org/10.1177/0956797609357327.

Kendon, A. (1995). Gestures as illocutionary and discourse structure markers in Southern Italian conversation. Journal of Pragmatics, 23(3), 247-279. https://doi.org/10.1016/ 0378-2166(94)00037-f.

Kendon, A. (2004). Gesture: Visible action as utterance. Cambridge: Cambridge University Press.

Kendon, A. (2008). Some reflections on the relationship between 'gesture' and 'sign'. Gesture, 8(3), 348-366. https://doi.org/10.1075/gest.8.3.05ken.

Kimmelman, V., Klezovich, A., \& Moroz, G. (2018). Iconicity patterns in sign languages. Retrieved from. https://sl-iconicity.shinyapps.io/iconicity_patterns/.

Kita, S., Alibali, M. W., \& Chu, M. (2017). How do gestures influence thinking and speaking? The gesture-for-conceptualization hypothesis. Psychological Review, 124(3), 245-266. https://doi.org/10.1037/rev0000059.

Kita, S., van Rijn, H., \& van der Hulst, H. (1997). Movement phases in signs and co-speech gestures, and their transcription by human coder. In M. Wachsmuth, I. \& Fröhlich (Ed.), Gesture and sign language in human-computer interaction, International Gesture Workshop Bielefeld Proceedings Lecture Notes in Artificial Intelligence (pp. 23-35). Berlin: Springer-Verlag.

Klima, E., \& Bellugi, U. (1979). The signs of language. Harvard: Harvard University Press.

Koelewijn, T., van Schie, H. T., Bekkering, H., Oostenveld, R., \& Jensen, O. (2008). Motorcortical beta oscillations are modulated by correctness of observed action. NeuroImage, 40(2), 767-775. https://doi.org/10.1016/j.neuroimage.2007.12.018.

Krauss, R. M. (1998). Why do we gesture when we speak? Current Directions in Psychological Science, 7(2), 54-60. https://doi.org/10.1111/1467-8721.ep13175642.

Labeye, E., Oker, A., Badard, G., \& Versace, R. (2008). Activation and integration of motor components in a short-term priming paradigm. Acta Psychologica, 129(1), 108-111. https://doi.org/10.1016/j.actpsy.2008.04.010.

Ladewig, S. H., \& Bressem, J. (2013). A linguistic perspective on the notation of form features in gestures. Body-language-communication: An international handbook on multimodality in human interaction (pp. 1079-1098).

Lagacé, S., \& Guérard, K. (2015). When motor congruency modulates immediate memory for objects. Acta Psychologica, 157, 65-73. https://doi.org/10.1016/j.actpsy.2015.02. 009.

Langacker, R. (2008). Cognitive Grammar: A basic introduction. Oxford, UK: Oxford University Press.

Lieberth, A. K., \& Gamble, M. E. (1991). The role of iconicity in sign language learning by hearing adults. Journal of Communication Disorders, 24(2), 89-99. https://doi.org/10. 1016/0021-9924(91)90013-9.

Marshall, C. R., \& Morgan, G. (2015). From gesture to sign language: Conventionalization of classifier constructions by adult hearing learners of British Sign Language. Topics in Cognitive Science, 7(1), 61-80. https://doi.org/10.1111/tops.12118.

McNeill, D. (1992). Hand and mind: What gestures reveal about thought. Chicago: University of Chicago Press.

Meir, I., Aronoff, M., Börstell, C., Hwang, S. O., Ilkbasaran, D., Kastner, I., ... Sandler, W. (2017). The effect of being human and the basis of grammatical word order: Insights from novel communication systems and young sign languages. Cognition, 158, 189-207. https://doi.org/10.1016/j.cognition.2016.10.011.

Müller, C. (2013). Gestural modes of representation as techniques of depcition. In C. Müller, A. Cienki, S. Ladewig, D. McNeill, \& J. Bressem (Eds.). Body - Language Communication: An International Handbook on Multimodality in Human Interaction (pp 1687-1701). Berlin: De Gruyter Mouton.

Müller, C. (2016). From mimesis to meaning: A systematics of gestural mimesis for concrete and abstract referenital gestures. Meaning, mind and communication: Explorations in cognitive semiotics (Zlatev, J.). Frankfurt am Main. Peter Lang.

Müller, C. (2018). Gesture and sign: Cataclysmic break or dynamic relations? Frontiers in Psychology, 9(September), 1651. https://doi.org/10.3389/fpsyg.2018.01651.
Nation, I. S. P. (2001). Learning vocabulary in another language. Cambridge: Cambridge University Press.

Nyst, V. (2016). The depiction of size and shape in gestures accompanying object descriptions in Anyi (Côte d'Ivoire) and in Dutch (The Netherlands). Gesture, 15(2), 156-191. https://doi.org/10.1075/gest.15.2.02nys.

Occhino, C., Anible, B., Wilkinson, E., \& Morford, J. P. (2017). Iconicity is in the eye of the beholder. How language experience affects perceived iconicity. Gesture, 16(1), $100-126$.

Ortega, G., \& Morgan, G. (2010). Comparing child and adult development of a visual phonological system. Language, Interaction, and Acquisition, 1(1), 67-81. https://doi. org/10.1075/lia.1.1.05ort.

Ortega, G., \& Özyürek, A. (2016). Generalisable patterns of gesture distinguish semantic categories in communication without language. In A. Papafragou, D. Grodner, D. Mirman, \& J. Trueswell (Eds.), Proceedings of the 38th Annual Meeting of the Cognitive Science Society (CogSci 2016) (pp. 1182-1187). Austin, TX.: Cognitive Science Society, Inc.

Ortega, G., \& Özyürek, A. (2019). Systematic mappings between semantic categories and types of iconic representations in the manual modality: A normed database of silent gesture. Behavior and Research Methods. https://doi.org/10.3758/s13428-01901204-6.

Ortega, G., Schiefner, A., \& Ozyurek, A. (2019). Hearing non-signers use their gestures to predict iconic form-meaning mappings at first exposure to signs. Open Science Framework. https://doi.org/10.17605/OSF.IO/W5F9T.

Ortega, G., Sümer, B., \& Ozyürek, A. (2017). Type of iconicity matters in the vocabulary development of signing children. Developmental Psychology, 53(1), 89-99.

Özyürek, A., Willems, R. M., Kita, S., \& Hagoort, P. (2007). On-line integration of semantic information from speech and gesture: Insights from event-related brain potentials. Journal of Cognitive Neuroscience, 19(4), 605-616. https://doi.org/10.1162/ jocn.2007.19.4.605.

Padden, C., Hwang, S.-O., Lepic, R., \& Seegers, S. (2015). Tools for language: Patterned iconicity in sign language nouns and verbs. Topics in Cognitive Science, 7(1), 81-94. https://doi.org/10.1111/tops.12121.

Padden, C., Meir, I., Hwang, S.-O., Lepic, R., Seegers, S., \& Sampson, T. (2013). Patterned iconicity in sign language lexicons. Gesture, 13(3), 287-305.

Peeters, D., Dijkstra, T., \& Grainger, J. (2013). The representation and processing of identical cognates by late bilinguals: RT and ERP effects. Journal of Memory and Language, 68(4), 315-332. https://doi.org/10.1016/j.jml.2012.12.003.

Perlman, M., \& Lupyan, G. (2018). People can create iconic vocalizations to communicate various meanings to Naïve Listeners. Scientific Reports, 8(1), 2634. https://doi.org/ 10.1038/s41598-018-20961-6.

Perniss, P., Özyürek, A., \& Morgan, G. (2015). The influence of the visual modality on language structure and conventionalization: Insights from sign language and gesture. Topics in Cognitive Science, 7(Special Issue), 2-11.

Perniss, P., \& Vigliocco, G. (2014). The bridge of iconicity : From a world of experience to the experience of language The bridge of iconicity : From a world of experience to the experience of language. Philosophical Transactions of the Royal Society of London. Series B, Biological Sciences, 369(20130300).

Pettenati, P., Sekine, K., Congestrì, E., \& Volterra, V. (2012). A Comparative study on representational gestures in Italian and Japanese Children. Journal of Nonverbal Behavior, 36(2), 149-164. https://doi.org/10.1007/s10919-011-0127-0.

Pietrandrea, P. (2002). Iconicity and arbitrariness in Italian Sign Language. Sign Language Studies, 2(3), 296-321. https://doi.org/10.1353/sls.2002.0012.

Pizzuto, E., \& Volterra, V. (2000). Iconicity and transparency in Sign Languages: A crosslinguistic cross-cultural view. In K. Emmorey, \& H. L. Lane (Eds.). The signs of language revisited: An anthology to Honor Ursula Bellugi and Edward Klima (pp. 229-250). Mahwah, N. J.: Lawrence Erlbaum Associates.

Rizzolatti, G., Fadiga, L., Gallese, V., \& Fogassi, L. (1996). Premotor cortex and the recognition of motor actions. Cognitive Brain Research, 3(2), 131-141. https://doi.org/ 10.1016/0926-6410(95)00038-0.

Roomer, E. K., Hoogerwerf, A. C., \& Linn, D. E. (2011). Boston benoem taak 2011. Utrecht.

Sandler, W. (2018). The body as evidence for the nature of language. Frontiers in Psychology, 9(Oct), 1-21. https://doi.org/10.3389/fpsyg.2018.01782.

Sandler, W., \& Lillo-Martin, D. (2006). Sign Language and Linguistic Universals. Cambridge: Cambridge University Press.

Schouwstra, M., \& De Swart, H. (2014). The semantic origins of word order. Cognition, 131(3), 431-436. https://doi.org/10.1016/j.cognition.2014.03.004.

Sidhu, D. M., \& Pexman, P. M. (2017). Five mechanisms of sound symbolic association. Psychonomic Bulletin and Review, 1-25. https://doi.org/10.3758/s13423-017-1361-1.

Singmann, H., Bolker, B., Westfall, J., \& Aust, F. (2019). afex: Analysis of factorial experiments. R package. Retrieved from $<$ https://cran.r-project.org $/$ package $=$ afex $>$.

Sloetjes, H., \& Wittenburg, P. (2018). ELAN (version 5.2). Nijmegen: Max Planck Institute for Psycholinguistics. Retrieved from < https://tla.mpi.nl/tools/tla-tools/elan/ > .

Taub, S. (2001). Language from the body: Iconicity and metaphor in American Sign Language Cambridge: Cambridge University Press.

van der Kooij, E. (2002). Phonological Categories in Sign Language of the Netherlands: The Role of Phonetic Implementation and Iconicity. Utrecht: LOT.

van Kesteren, M., Rijpkema, M., Ruiter, D., Morris, R., \& Fernandez, G. (2014). Building on prior knowledge: Schema-dependent encoding processes relate to academic performance. Journal of Cognitive Neuroscience, 26(10), 2250-2261. https://doi.org/10. 1162/jocn.

van Nispen, K., van de Sandt-Koenderman, M., Mol, L., \& Krahmer, E. (2014). Pantomime Strategies: On Regularities in How People Translate Mental Representations into the Gesture Modality. In Proceedings of the 36th annual conference of the cognitive science society (CogSci 2014) (pp. 3020-3026). Austin, TX: Cognitive Science 
Society, Inc.

Van Nispen, K., Van De Sandt-Koenderman, W. M. E., \& Krahmer, E. (2017). Production and comprehension of pantomimes used to depict objects. Frontiers in Psychology, 8(July), 1095. https://doi.org/10.3389/FPSYG.2017.01095.

Vigliocco, G., Perniss, P., \& Vinson, D. (2014). Language as a multimodal phenomenon: Implications for language learning, processing and evolution. Philosophical Transactions of the Royal Society of London. Series B, Biological Sciences, 369(20130292).
Vinson, D., Thompson, R. L., Skinner, R., \& Vigliocco, G. (2015). A faster path between meaning and form? Iconicity facilitates sign recognition and production in British Sign Language. Journal of Memory and Language, 82, 56-85. https://doi.org/10.1016/ j.jml.2015.03.002.

Yap, D.-F., So, W.-C., Yap, J.-M. M., Tan, Y.-Q., \& Teoh, R.-L. S. (2011). Iconic gestures prime words. Cognitive Science, 35(1), 171-183. https://doi.org/10.1111/j.1551 6709.2010.01141.x. 